This PDF is a selection from a published volume from the National Bureau of Economic Research

Volume Title: Housing and the Financial Crisis

Volume Author/Editor: Edward L. Glaeser and Todd Sinai, editors

Volume Publisher: University of Chicago Press

Volume ISBN: 978-0-226-03058-6

Volume URL: http://www.nber.org/books/glae11-1

Conference Date: November 17-18, 2011

Publication Date: August 2013

Chapter Title: Can Cheap Credit Explain the Housing Boom?

Chapter Author(s): Edward L. Glaeser, Joshua D. Gottlieb, Joseph Gyourko

Chapter URL: http://www.nber.org/chapters/c12622

Chapter pages in book: (p. 301 - 359) 


\title{
Can Cheap Credit Explain the Housing Boom?
}

\author{
Edward L. Glaeser, Joshua D. Gottlieb, \\ and Joseph Gyourko
}

\subsection{Introduction}

From the beginning of 2001 to its cyclical peak in April of 2006, the Standard and Poor's/Case-Shiller Twenty City Composite Index rose by nearly 60 percent in real terms and then fell by just over one-third before reaching a plateau in May of 2009. The volatility of the Federal Housing Finance Agency (FHFA) repeat-sales price index was less extreme but still severe. That index rose by just over 50 percent in real terms between 1996 and 2006 and then fell by 19 percent in real terms between the end of 2006 and the end of 2009. The real value of this index fell by another 11 percent as of the fourth quarter of $2011 .{ }^{1}$ As many financial institutions had invested

Edward L. Glaeser is the Fred and Eleanor Glimp Professor of Economics at Harvard University and a research associate and director of the Urban Economics Working Group at the National Bureau of Economic Research. Joshua D. Gottlieb is assistant professor of economics at the University of British Columbia. Joseph Gyourko is the Martin Bucksbaum Professor of Real Estate and chairperson of the Real Estate Department at the Wharton School, University of Pennsylvania, and a research associate of the National Bureau of Economic Research.

We are grateful to our discussants, Gadi Barlevy and Morris Davis; to an anonymous reviewer; to Thomas Barrios, Owen Lamont, Carolin Pflueger, Jeremy Stein, Paul Willen, Justin Wolfers, and seminar participants at Harvard University, the University of Pennsylvania, the NBER conference on "Housing Markets and the Financial Crisis," the 2010 AREUEA MidYear Meetings, and the 2010 Conference on Urban and Regional Economics for valuable comments; and to Fernando Ferreira, Karen Pence, and Amit Seru for providing data. Jiashou Feng and Charlie Nathanson provided excellent research assistance. Glaeser and Gottlieb thank the Taubman Center for State and Local Government for financial support. Gottlieb also thanks the Harvard Real Estate Academic Initiative and the Institute for Humane Studies. Gyourko thanks the Research Sponsors Program of the Zell/Lurie Real Estate Center at Wharton. For acknowledgments, sources of research support, and disclosure of the authors' material financial relationships, if any, please see http://www.nber.org/chapters/c12622.ack.

1. The monthly index values for the Standard \& Poor's/Case-Shiller Index are available at http://www.standardandpoors.com/indices/sp-case-shiller-home-price-indices/en 
in or financed housing-related assets, the price decline helped precipitate enormous financial turmoil.

Much academic and policy work has focused on the role of interest rates and other credit market conditions in this great boom-bust cycle. One common explanation for the boom is that easily available credit, perhaps caused by a "global savings glut," led to low real interest rates that substantially boosted housing demand and prices (e.g., Himmelberg, Mayer, and Sinai 2005; Mayer and Sinai 2009; Taylor 2009). Others have suggested that easy credit market terms, including low down payments and high mortgage approval rates, allowed many people to act at once and helped generate large, coordinated swings in housing markets (Khandani, Lo, and Merton 2009). Favilukis, Ludvigson, and Van Nieuwerburgh (2010) have argued that the relaxation of credit constraints combined with a decline in housing transactions costs can account for much of the recent boom. These easy credit terms may themselves have been a reflection of agency problems associated with mortgage securitization (Keys et al. 2009, 2010; Mian and Sufi 2009, 2010; Mian, Sufi, and Trebbi 2008).

If correct, these theories provide economists with the comfortable sense that we understand one of the great asset market gyrations of our time; they would also have potentially important implications for monetary and regulatory policy. However, economists are far from reaching a consensus about the causes of the great housing market fluctuation. Shiller $(2005,2006)$ long has argued that mass psychology is more important than any of the mechanisms suggested by the research cited earlier. Skeptics of an especially strong role for interest rates include Glaeser and Gyourko (2008) and Greenspan (2010). Bubb and Kaufman (2009) provide a counterpoint to the argument that agency conflicts within mortgage securitization programs contributed to the issuance of significantly riskier loans.

This uncertainty leads us to reevaluate the link between housing markets and credit market conditions, to determine if there are compelling conceptual or empirical reasons to believe that changes in credit conditions can explain the past decade's housing market experience. For credit markets to be able to explain the large recent price movements, there must have been a substantial change in credit market conditions during the periods when housing prices were booming and busting, and credit markets must influence house prices.

Certainly, the real long rate dropped substantially during the housing boom, and the implied impact of interest rates on house prices is quite large according to the static version of Poterba's (1984) asset market approach to house valuation. Between 1996 and 2006, the real ten-year Treasury yield

/us/?indexId=spusa-cashpidff--p-us----. We use the seasonally-adjusted monthly figures as of May 2012 for the twenty-city index and the relevant monthly All Urban Workers Consumer Price Index (CPI-U) from the Bureau of Labor Statistics to compute real changes. The FHFA series is downloadable at http://www.fhfa.gov/Default.aspx?Page=87, and we used index numbers as of 2012(1). 
fell by 120 basis points, and declined by an even larger 190 basis points from 2000 to 2005, when housing prices boomed the most. Recent research implies a semielasticity of housing prices with respect to real rates of over 20 (Himmelberg, Mayer, and Sinai 2005, hereafter HMS), meaning that a 100 basis point change in real rates should be associated with roughly a 20 percent increase in price. $^{2}$ The combination of a nearly 200 basis point decline in real interest rates and semielasticity of 20 suggests that the change in real rates could account for the bulk of the 50 percent-plus boom in prices experienced in the aggregate US data.

But there are two reasons to question this conclusion. First, a more comprehensive user cost model, which we present in section 7.2 of this chapter, predicts much lower price impacts than suggested by those using Poterba's (1984) framework (e.g., HMS 2005). Second, the actual empirical relationship between house prices and interest rates is much weaker than that implied by the standard pricing model used in housing market analysis.

The model analyzed in section 7.2 illustrates various reasons why the impact of interest rates in particular may be much less strong than has been traditionally suggested by the asset market approach to house prices. First, the link between house prices and interest rates can be reduced substantially by weakening the connection between private discount rates and market interest rates. The standard asset market approach presumes that private discount rates and market rates always move together. This relationship means that lower current rates raise the present value of future appreciation, and hence increase current willingness to pay. The sizable impact of current discount rates on the value of future gains leads standard models to predict a large impact of interest rates on prices, especially in high price growth environments. But if private discount rates do not move with market rates, because buyers are credit constrained, then this channel is eliminated, and the connection between interest rates and prices is substantially muted.

The nature of housing supply provides another reason why interest rate effects need not be large, at least in some markets. If supply is highly elastic in the relatively short run, then house prices should be pinned down by fundamental production costs, as suggested by Glaeser, Gyourko, and Saiz (2008). In that case, any demand shifter, whether interest rate-related or not, simply engenders sufficient new production to keep prices from rising above the level where developers can cover all production costs and earn a normal entrepreneurial profit.

While it certainly is possible that buyers are not as forward-looking as our extensions of the Poterba model presume, the essence of any asset market approach to house valuation is that buyers form expectations about future price changes. More generally, we are quite open to the possibility

2. The semielasticity is defined as the derivative of the logarithm of housing prices with respect to the real interest rate. 
that buyers are far less rational than these models suggest, but there is no consensus yet on the right alternative to rational expectations. Certainly, it is a mistake to think that standard economic reasoning necessarily predicts an extremely strong relationship between interest rates and housing prices.

In Glaeser, Gottlieb, and Gyourko (2010), we also show that when interest rates are volatile and mean revert, expected mobility and the ability to refinance can also reduce the predicted interest rate elasticity of house prices by three-quarters. If buyers in low-interest rate environments anticipate having to sell their homes in periods with higher rates, the link between current rates and house prices is weakened. Another mechanism muting the impact of higher rates is that buyers may anticipate the ability to access lower rates in the future via refinancing. As long as buyers also anticipate that current rates will not remain low (or high) in perpetuity, the interest rate elasticity of house prices will be lower.

As we document in section 7.3, the data largely are consistent with the modest implied semielasticity of house prices with respect to interest rates implied by our expanded model. For example, the simple bivariate relationship between log house prices and the real long rate, as measured by the ten-year Treasury rate corrected for inflation expectations, implies that a 100 basis point fall in rates is associated with barely a 7 percent increase in house prices, as measured by the FHFA index between 1980 and 2008. Larger price effects are found by restricting the sample to years after 1984, but they do not survive inclusion of a simple national time trend. As theory suggests, we find that real rates have their strongest impact when rates are low and in markets where housing supply is relatively inelastic. Our results support HMS's (2005) insight that price impacts should be stronger at lower initial rates of interest, but even when rates change from a low base, a 100 basis point fall in real rates is associated with only an 8 percent rise in real house prices, independent of trend.

While there are good reasons to question the empirical authority of less than thirty years of time series data, these results are quite in line with the predictions of our model. Thus, both theory and data suggest that lower real rates cannot account for more than one-fifth of the boom in house prices.

We then use our estimated coefficients to assess the portion of the price increase that can be explained by interest rate changes over different time periods: (a) the full boom period of 1996 to 2006; (b) the period of largest change in rates; and (c) the initial housing bust of 2006 to 2008. Assuming that the semielasticity of prices with respect to the interest rate is 6.8 , the 120 basis point drop in the real long rate between 1996 and 2006 predicts a price increase of about 8 percent, which is less than one-fifth of the actual increase in prices over this period. If we cherry-pick the time period and focus on the years from 2000 to 2005 during which real rates changed most, we find that declining rates can explain almost 45 percent of the 29 percent real price increase that actually occurred during that period. But, this truly 
is cherry picking, as real rates also fell during the bust since 2006, and obviously cannot account for the fall in prices in that period.

These results should not, however, be interpreted as suggesting that monetary policy was either wise or appropriate. Housing is only part of the economy, and monetary policy should be evaluated in a broader context. Even within the housing sector, it is possible that a sharp rise in the Federal Funds rate could have substantially limited price increases by interacting with buyers' expectations during the boom. But this speculation only highlights the need for more research on the broader issue of buyers' expectations.

In sections 7.4 and 7.5, we investigate two other changes in mortgage credit markets: mortgage approval rates and down payment requirements. One difficulty with assigning much credit, or blame, for the boom to these factors is that the measured values of both variables seem to have remained remarkably constant over the housing cycle. For example, Home Mortgage Disclosure Act (HMDA) data show that approval rates were 78 percent in 2000 and in 2005. The median loan-to-value (LTV) ratio among buyers in our data was no higher in 2005 than in 1999. And, our data indicate that there is nothing new about having at least 10 percent of purchasers buying with little or no equity. ${ }^{3}$

That said, there is good reason to be skeptical about interpreting either data series as signaling little or no change in effective credit conditions. For example, if the quality of loan applicants declined substantially during the boom, then relatively constant approval rates or loan-to-value ratios could, in fact, reflect much easier credit conditions. The number of applications did trend up sharply during the boom, and characteristics of that pool also changed (e.g., the number of single applicants as opposed to twoperson applications spiked, minority applicants increased more than white applicants, etc.). We try to infer an underlying approval rate series from the available data in several ways. First, we just assume an upward trend in the number of ill-qualified people applying for mortgages. Second, we assume that a fixed fraction of the growth in the number of accepted mortgage applications reflects growth in approval rates. Both of these approaches suggest that the true underlying approval rate could have increased substantially over the boom.

To estimate the impact that rising approval rates or changing loanto-value ratios should have had on price, we then need to multiply the growth in approval rates by a coefficient linking approval rates and prices. Our model predicts only modest impacts for each. Down payments should matter when private discount rates and market rates are not identical. After all, if you can borrow and lend at the same rate, you are indifferent between

3. The loan-to-value data are from DataQuick, a private data vendor to the real estate industry, and are discussed more fully later in the chapter. 
paying all cash or leveraging your home purchase. Even if borrowers are credit constrained and private discount rates are very high (i.e., well above 10 percent), the implied semielasticity of lowering down payments never exceeds two, according to our model. Hence, even very large changes of 10 percentage points in loan-to-value ratios would lead to no more than a 20 percent change in house prices.

The most natural interpretation of a higher approval rate is that it boosts the demand for housing. Thus, if lenders change from approving 50 percent of would-be buyers to approving 60 percent of would-be buyers, that essentially reflects a 20 percent increase in the market demand for housing. Given standard housing supply elasticities of two and demand elasticity estimates of less than one, this would be associated with less than a 7 percent increase in prices. The model's predictions of modest marginal effects on prices are largely confirmed in the data. However, important endogeneity concerns make robust analysis of these variables difficult. Empirically, we do not have strong instruments to deal with the likelihood that bank behavior regarding lending conditions not only could influence the housing market, but could be influenced by it.

Using our theory-inspired elasticity of prices with respect to approval rates, and our implied approval rate series, we estimate that even a large increase in approval rates should have predicted a price increase of no more than 14 percent, which is one-quarter of the increase that America experienced. We can, however, explain the post-2006 decline.

Still, the combination of standard econometric concerns about the robustness of estimated marginal effects on prices with worries about the measurement of these two credit market variables themselves means that no firm conclusions can be reached about the role of these particular aspects of the credit market. We find no evidence that these factors did account for the boom and bust in house prices, but that is very different from convincingly concluding they did not play a more prominent role. More research with different and better data will be needed to pin down their effects empirically.

Similar conclusions hold for loan-to-value ratios. Since they did not increase by much on average over the boom, they could not explain it, even if we had estimated large marginal effects on house prices. Unlike interest rates and like approval rates, loan-to-value ratios move in the right direction to help account for the 2006 to 2008 bust.

In sum, we doubt that any single or simple story can explain the movement in house prices, especially over the past decade. While our analysis indicates that one plausible explanation of that boom, easy credit conditions - and low interest rates especially — cannot account for most of what happened to prices, we are not able to offer a compelling alternative hypothesis. We suspect that Case and Shiller (2003) are correct and the overoptimism illustrated by their surveys of recent home buyers was critical, but this just pushes the puzzle back a step. Why were buyers so overly optimistic about prices? Why 
did that optimism show up during the early and middle years of the last decade, and why did it show up in some markets but not others? Irrational expectations are surely not exogenous, so what explains them?

\subsection{The Theoretical Link between Interest Rates and Housing Prices}

In this section, we follow the path laid out by Poterba (1984) and reevaluate the theoretical predictions about the connection between interest rates, housing prices, and other credit market variables. The myriad challenges in empirically estimating the connection between these variables and prices increase the value of simple, robust theoretical predictions about these relationships. We have chosen a simple model, close in spirit to the benchmark user cost model, that treats interest rates and other credit market variables such as approval rates and loan-to-value ratios as exogenous variables that have the potential to influence housing prices and quantities.

We begin by analyzing interest rates, and follow the literature in this part. There is less guidance from the literature on how to approach loan-to-value ratios and approval rates. To model approval rates, we will assume that there is a fraction of the population each period that is kept out of the housing market because they cannot get credit. We assume that an increase in approval rates is a reduction in the share of people who cannot get loans, and that will operate essentially as a shift outward in the demand for housing. Changes in loan-to-value ratios may also operate by enabling formerly credit constrained people to buy homes, but we separate out the approval effect from the loan-to-value effect. In our model, higher loan-to-value ratio will raise housing demand because formerly credit constrained people are now able to take out larger loans.

In the first subsection, we assume that the housing stock is fixed, rents are constant, and prices are determined so that buyers will be financially indifferent between owning and renting. Within that framework, we provide a closed-form solution when interest rates are time invariant, and in Glaeser, Gottlieb, and Gyourko (2010) we show simulated results when interest rates follow a stochastic process. In the second subsection, we endogenize housing supply in the location in question. In that case, home buyers are not only indifferent between buying and renting, but also between living in the impacted community and a reservation locale.

\subsubsection{Fixed Housing Supply and Fixed Interest Rates}

We focus on the choice of a consumer moving to a particular area in year $t$, who is deciding whether to buy or rent a home. Equilibrium requires the marginal consumer to be indifferent between the two choices, and if consumers are homogeneous, then everyone will be indifferent between buying and renting.

In this subsection, we treat housing supply and rent as exogenous. We 
further assume that the home owners and renters are homogenous, riskneutral, and face random mobility shocks. With probability $\delta$ each period, a shock will force the consumer to vacate his or her new home or rental property. This shock might be a taste shock (e.g., a divorce or a marriage) or an economic shock (e.g., a new job opportunity elsewhere).

If the consumer chooses to rent, she pays the rental rate $R_{t+j}$ in each period $t+j \geq t$ as long as she remains in this unit. If she chooses to buy, she is required to make a down payment of $\theta$ times the price, which is denoted $P_{t}$. Home owners finance the rest of the mortgage, rolling over the debt each period at an interest rate $r$ per period. Thus the nominal debt is kept constant at $(1-\theta) P_{t}$ until they move out. We deflate the interest rate cost by $1-\varphi$, where $\varphi$ should be thought of as the relevant tax rate, to reflect the deductibility of mortgage payments (all costs should be thought of as being paid in after-tax dollars). Owners must also pay property taxes (also corrected for federal tax deductibility) and maintenance costs in period $t+j$ equal to $\tau(1+g)^{j} P_{t}$, where $g$ is the growth rate of maintenance expenditures.

Our first approach to valuing the home follows the usual method of treating the rental flow as exogenous, and derives a standard pricing formula. We assume that there are no cash constraints, and that renting and owning must have equal expected costs spread over the (uncertain) duration of the individual in the locale.

We consider the discounted flow of costs as of time $t$. That is, expenditures at time $t+j$ are discounted at an annual rate of $\rho$. We assume that rental and interest payments come at the end of each period. The expected outlays from renting over the duration of the lease are therefore:

$$
\sum_{j=1}^{\infty}\left(\frac{1-\delta}{1+\rho}\right)^{j} \frac{1}{1-\delta} R_{t+j-1} .
$$

Assuming that rents grow at a constant rate $g$ equal to the growth of maintenance costs, so that $R_{t}+{ }_{j}=(1+g)^{j} R_{t}$, then the net present value of expected rental payments is $R_{t} /\left(\rho_{t}+\delta+\delta g-g\right)$.

In the case of buying with a down payment of $\theta P_{t}$, the expected costs of ownership are the expected value of:

$$
\theta P_{t}+\sum_{j=1}^{\infty}\left(\frac{1-\delta}{1+\rho}\right)^{j} \frac{1}{1-\delta}\left\{\begin{array}{c}
r(1-\varphi)(1-\theta) P_{t}+\tau(1+g)^{j-1} P_{t} \\
-\delta\left[P_{t+j}-(1-\theta) P_{t}\right]
\end{array}\right\} .
$$

The first term, $\theta P_{t}$, represents the required down payment. To this is added the sum of future expected interest rate payments (equal to $r(1-\varphi)(1-\theta) P_{t}$ in each period) and future maintenance and property tax payments (equal to $\tau(1+g)^{j-1} P_{t}$ in each period). Finally, we subtract capital appreciation (equal to $P_{t+j}-(1-\theta) P_{t}$ when the sale finally occurs).

The net present value of housing costs to an owner is thus: 


$$
P_{t}\left(\frac{\theta \rho+(1-\theta)(1-\varphi) r-g+\tau+g(1-\theta)(1-\delta)^{\frac{\rho-(1-\varphi) r}{\rho+\delta}}}{\rho+\delta+g \delta-g}\right) .
$$

If the net present values of renting and owning costs are equal, then the rent-to-price ratio will satisfy:

$$
\frac{R_{t}}{P_{t}}=\theta \rho+(1-\theta)(1-\varphi) r-g+\tau+g(1-\theta)(1-\delta) \frac{\rho-(1-\varphi) r}{\rho+\delta} .
$$

This purely static formula is analogous to the one used by Poterba (1984) and HMS (2005). This formula does not allow us to consider elastic housing supply, but it does allow us to explore another critical issue: the connection between the private discount rate and market interest rates.

The asset market approach to housing prices typically assumes that future costs are discounted at the market rate of interest net of taxes. This is natural if individuals are investing funds at this market rate. In that case, an investment of one dollar at time $t$ yields a return of $[1+(1-\varphi) r]^{j}$ at time $t+j$, and the rent-to-price formula simplifies to $R_{t} / P_{t}=(1-\varphi) r-g+\tau$. This formula can also be understood in real terms. If the inflation rate is denoted $\pi$, the real growth of the rental rate (and housing prices) is denoted $\hat{g}$ and the real interest rate is denoted $\hat{r}$, then $R_{t} / P_{t}=(1-\varphi) \hat{r}-\hat{g}-\varphi \pi+\tau$. As Poterba (1984) taught us, higher rates of inflation will increase the tax subsidy to housing and raise the level of prices relative to rents. These standard formulae also suggest that down payment requirements have no impact since the market and private rates of interest are identical.

But individuals need not discount the future at the market interest rate. Some home buyers, especially young ones, are likely to have little or no other assets and be credit-constrained in their spending on other goods (Mayer and Engelhardt 1996; Haurin, Wachter, and Hendershott 1995). If so, they may discount future gains at a rate that is both higher than the market rate and potentially varies independently of the market rate. Because investing in owner-occupied homes is challenging for the large institutional investors who probably set prices in liquid securities markets (e.g., government bonds), it seems plausible for the marginal investor to be one of these constrained households, and hence for the pricing kernel to vary between housing and securities markets.

To explore the implications of this segmentation, we let $\rho=\hat{\rho}(\hat{r})+(1-\varphi)$ $\pi$, so that the real private discount rate, $\hat{\rho}(r)$, can respond to the market interest, $\hat{r}$, but need not move one-for-one. The rent-to-price ratio is then:

$$
\begin{aligned}
\frac{R_{t}}{P_{t}}= & \hat{\rho}(\hat{r})-\varphi \pi+(1-\theta)(1-\varphi) \hat{r}-\hat{g}+\tau \\
& +(\hat{g}+\pi)(1-\theta)(1-\delta) \frac{\hat{\rho}(\hat{r})-(1-\phi) \hat{r}}{\hat{\rho}(\hat{r})+(1-\phi) \pi+\delta} .
\end{aligned}
$$


If rents $\left(R_{t}\right)$, inflation $(\pi)$, and the growth rate of rents and maintenance $(\hat{g})$ are held constant, the derivative of the log price with respect to the real market rate of interest $(\hat{r})$ is:

$$
\begin{aligned}
& \frac{\partial \operatorname{Ln}\left(P_{t}\right)}{\partial \hat{r}} \\
& \quad=-\frac{(1-\varphi)\left[1-\theta-\frac{(\hat{g}+\pi)(1-\theta)(1-\delta)}{\hat{\rho}(\hat{r})+(1-\varphi) \pi+\delta}\right]+\hat{\rho}^{\prime}(\hat{r})\left[\theta+\frac{(\hat{+}+\pi)(1-\theta)(1-\delta)((1-\varphi)(\hat{r}+\pi)+\delta)}{(\hat{\rho}(\hat{r})+(1-\varphi) \pi+\delta)^{2}}\right]}{\theta \hat{\rho}(\hat{r})-\varphi \pi+(1-\theta)(1-\varphi) \hat{r}-\hat{g}+\tau+(\hat{g}+\pi)(1-\theta)(1-\delta) \frac{\hat{\rho}(\hat{r})-(1-\varphi) \hat{r}}{\hat{\rho}(\hat{r})+(1-\varphi) \pi+\delta}} .
\end{aligned}
$$

This quantity is decreasing with $\hat{\rho}^{\prime}(\hat{r})$, so a higher sensitivity of private discount rates to public interest rates makes those interest rates more powerful in determining prices.

Two natural benchmarks for this relationship are when $\hat{\rho}^{\prime}(\hat{r})=(1-\varphi)$, which is the case assumed by the asset market approach (i.e., private home buyers discount at the market rate), and when $\hat{\rho}^{\prime}(\hat{r})=0$, where discounting depends purely on private preferences and is independent of real market rates. We calibrate the semielasticity under these two assumptions, shown in table 7.1. We first assume that the market rate and the private discount rate are the same, so that $\hat{\rho}(\hat{r})=(1-\varphi) \hat{r}$; and then in column (2), we assume that these variables are decoupled. Within each column, we compute the semielasticity for a range of interest rates.

For our benchmark semielasticities, shown in column (1), we assume that $\hat{g}=0.01$, which corresponds to an average real growth rate of housing prices of 1 percent. We let $\pi=0.032$, which corresponds to the average inflation rate over the past quarter century. We let the real interest rate range from 3 percent $(\hat{r}=0.03)$, which corresponds to a nominal rate of 7.2 percent, to 7 percent $(\hat{r}=0.07)$. The marginal tax rate is 25 percent $(\varphi=0.25)$. We assume a 20 percent down payment requirement $(\theta=0.2)$. In line with previous work in this area, we calibrate noninterest costs of home ownership to be 3.5 percent per year $(\tau=0.035$; Poterba and Sinai 2008). Individuals have a 6 percent chance of moving each year $(\delta=0.06)$, which is substantially lower than the typical US rate of changing residences (which is 15.5 percent) to reflect home owners' lower mobility. ${ }^{4}$ Perhaps most importantly, this calculation assumes that $\hat{\rho}(\hat{r})=(1-\varphi) \hat{r}=0.03$, so the private discount rate equals the marginal rate at the point where we are taking a derivative. This assumption, which we drop beginning in column (3), allows us to focus on the fact that the private rate may not move with the market rate, rather than the possibility that the private rate is substantially different from the market rate. ${ }^{5}$

4. Ferreira, Gyourko, and Tracy (2010) report a two-year mobility rate for home owners of 12 percent.

5. Technically, we assume that the private rate is epsilon larger than the market rate, so that market rate remains slightly below the private discount rate when the derivative is taken. 
Interest rate semielasticities with inelastic housing supply

\begin{tabular}{lrrrrrr}
\hline & $(1)$ & $(2)$ & $(3)$ & $(4)$ & $(5)$ & $(6)$ \\
\hline Discount rate linked? & Yes & Yes & No & No & No & No \\
Mobility $(\delta)$ & $6 \%$ & $6 \%$ & $6 \%$ & $6 \%$ & $0 \%$ & $6 \%$ \\
Down $(\theta)$ & $20 \%$ & $20 \%$ & $20 \%$ & $2 \%$ & $20 \%$ & $20 \%$ \\
Growth $(\hat{g})$ & $1 \%$ & $2 \%$ & $1 \%$ & $1 \%$ & $1 \%$ & $2 \%$ \\
Real interest rate & & & & & & \\
$\quad \hat{r}=0.03$ & -18.99 & -25.42 & -8.05 & -10.70 & -4.70 & -8.62 \\
$\hat{r}=0.04$ & -15.96 & -20.27 & -7.45 & -9.66 & -4.49 & -7.93 \\
$\hat{r}=0.05$ & -13.76 & -16.85 & -6.93 & -8.81 & -4.29 & -7.35 \\
$\hat{r}=0.06$ & -12.10 & -14.42 & -6.48 & -8.10 & -4.12 & -6.85 \\
$\hat{r}=0.07$ & -10.79 & -12.61 & -6.09 & -7.49 & -3.95 & -6.41 \\
\hline
\end{tabular}

Notes: This table reports calculated values of the semielasticity of house prices with respect to interest rates under various parameter assumptions. In the baseline scenario, shown in column (1), annual growth of rents and costs is $\hat{g}=0.01$, annual inflation is $\pi=0.032$, the marginal tax rate is $\varphi=0.25$, the down payment is $\theta=0.2$ of the purchase price, noninterest costs of homeownership are $\tau=0.035$, and annual mobility is $\delta=0.06$. When discount rates are linked to interest rates, $\hat{\rho}(\hat{r})=(1-\varphi) \hat{r}$, and $\hat{\rho}(\hat{r})=0.055$ otherwise. The semielasticity is evaluated at various initial real interest rates $\hat{r}$.

When the real interest rate is 0.03 (and hence the real private discount rate is 0.0225 ), the semielasticity is -19 , as reported in column (1). This represents a very high degree of price responsiveness, comparable to that discussed by HMS (2005). The magnitude drops to 16 if the real interest rate is 0.04 , which is reported in the next row of column (1). As the real rate rises to 0.07 , the elasticity drops down to about 11, but these results suggest a large impact of interest rates on prices unless real rates themselves are quite high.

The second column of table 7.1 increases the real growth rate of fundamental values and ownership costs from $\hat{g}=0.01$ to $\hat{g}=0.02$. This increases interest rate responsiveness by changing the potential for capital gains should the family move.

To begin exploring the impact of changing assumptions about the discount rate, we can simplify equation (3) under the baseline parameterization. With these values, at a real interest rate of $\hat{r}=0.03$, the semielasticity can be written as $-\left(\partial \log \left(P_{t}\right)\right) / \partial \hat{r}=8.3+10.2 \hat{\rho}^{\prime}(\hat{r})$. When $\hat{\rho}^{\prime}(\hat{r})=1-\varphi$, the case shown in column (1), the semielasticity is -16 . When discount rates are delinked from interest rates, so $\hat{\rho}^{\prime}(\hat{r})=0$, the semielasticity falls to -8.3 . The connection between $\hat{\rho}$ and $\hat{r}$ nearly doubles the predicted relationship between prices and interest rates. Lower levels of $\hat{r}$ or higher levels of $\hat{g}$ will raise the predicted relationship, but the sensitivity to $\hat{\rho}^{\prime}(\hat{r})$ remains. For instance, if $\hat{g}=0.02$, then $-\left(\partial \log \left(P_{t}\right)\right) / \partial \hat{r}=9.3+14.7 \hat{\rho}^{\prime}(\hat{r})$, in which case the semielasticity ranges from 9.3 to 20.3 .

Columns (3) through (6) of table 7.1 report results when interest rates and discount rates are no longer tied together. In this case, we assume that the discount rate is $\hat{\rho}(\hat{r})=0.055$. We chose this value so that $\hat{\rho}>(1-\varphi) \hat{r}$ for 
all of our values of $\hat{r}$. It is easy for us to imagine that individuals are more impatient than the market, but considerably harder to believe that they are more patient, since this would presumably lead them to invest up to the point where their marginal rate of substitutions between periods equals the market interest rate.

As column (3) demonstrates, eliminating the discount rate-interest rate connection cuts the semielasticity from 19 to 8 when $\hat{r}=0.03$ and from 8 to 6 when $\hat{r}=0.07$. Not only does the level of the semielasticity fall dramatically, but so does its sensitivity to $\hat{r}$. The impact of down payment requirements under this new assumption can be seen by comparing column (3) to column (4). In column (4), we reduce the down payment from $\theta=0.2$ to $\theta=0.02$, and find significantly higher elasticities at the lower value. They now range from 7.5 when $\hat{r}=0.07$ to 10.7 when $\hat{r}=0.03$. Higher rates now affect the buyers' choice set, making them more sensitive to these costs.

The fifth column eliminates mobility $(\delta=0)$ and shows substantially lower interest rate elasticities of around $4 .^{6}$ This result obtains because mobility reduces the amount of time that borrowers expect to pay the interest rate, and thereby increases the effective discount rates. This can be seen most clearly in the price-rent formula given in equation $\left(2^{\prime \prime}\right)$, where mobility $\delta$ is added to the discount rate $\rho$. The final column again increases the real growth rate from $\hat{g}=0.01$ to $\hat{g}=0.02$. As in the move from column (1) to column (2), this change increases interest rate sensitivity, but the effect here is smaller.

There are two reasons why the connection between market and private discount rates can matter so much. First, when private discount rates and market interest rates move together as in the standard asset market approach, higher market rates make future appreciation less valuable to a buyer, dampening housing demand. Similarly, lower rates increase the value of future price growth, raising demand and increasing the sensitivity of house prices to interest rates. However, if private discount rates do not move with market rates, then future price gains no longer become more valuable as market rates fall, and less valuable as rates rise. The second reason for the difference comes from the opportunity cost of the down payment. In the asset market approach, higher interest rates increase the opportunity cost of the down payment, but with a private discount rate, that is no longer the case.

While the link between discount rates and interest rates has a powerful impact on semielasticities, one further force that we do not investigate here is the introduction of stochastic interest rates. In Glaeser, Gottlieb, and Gyourko (2010), we show that when interest rates are volatile and mean revert, the current rate becomes dramatically less important for buyers than

6. In Glaeser, Gottlieb, and Gyourko (2010) we show that the effect of mobility is reversed when interest rates are mean-reverting. In that case, mobility reduces interest rate responsiveness because home owners anticipate having to sell when interest rates have returned back toward an average level. 
it is in the present model. This occurs for two reasons. Most directly, buyers who can refinance their mortgages need not pay the current interest rate indefinitely. Since the current rate no longer determines the cost of all future interest payments, it has less of an impact on buyers' demand. Even more significantly, volatile interest rates imply volatile house prices. If buyers in low interest rate environments anticipate having to sell their homes subsequently, and rates may have changed, they rationally expect to receive capital gains or losses from this sale. This expected reversion of prices further mutes the impact of current rates on buyers' willingness to purchase housing. The impact of interest rate volatility on the semielasticity with respect to current rates increases with home owners' mobility and with the ease of mortgage refinancing.

While this model aims to increase the realism of the user cost analysis, there are other channels by which credit costs could have driven price growth. We have modeled credit constraints as a disconnect between private and market discount rates, but looser borrowing constraints might foster a credit-driven demand from absentee investors. In addition, families' expectations of future price growth could change in the face of laxer credit conditions. Changing credit availability could also affect an area's composition, leading to multiplier effects through other buyers' purchase or default decisions. Finally, the static model we employ here does not permit us to examine the effects of interest rate changes on the numerous risk premia embodied in mortgages, or conversely of these premia on rates (Campbell and Cocco 2011). The time-varying rates we examine in Glaeser, Gottlieb, and Gyourko (2010) can be viewed as one reduced-form approach to modeling this risk.

We next enrich the model by incorporating explicit changes in down payment requirements and mortgage denials.

\subsubsection{The Impact of Down Payment Requirements on Prices}

Cheap credit could potentially influence housing prices through high loan-to-value ratios, easy approval rates, and a whole range of phenomenon often associated with, but not limited to, subprime lending (Coleman, LaCour-Little, and Vandell 2008). We now turn to the effect of down payment requirements and approval rates.

In our core model, there is a fixed supply of housing and essentially an infinite supply of homogenous buyers, which implies that there is no way to generate sensible predictions about approval rates. Under these model assumptions, rejecting 10 or 50 percent of prospective buyers will make no difference to price. Hence, we will consider the impact of approval rates only in the next section when we allow heterogeneity of buyers, which generates a downward sloping demand for housing, and an elastic housing supply.

The basic model can, however, generate implications about the impact of changes in down payment effects. In the case of a constant interest rate, 
differentiating the log of house price with respect to $\theta$, the down payment level, yields:

$$
\begin{aligned}
& \frac{\partial \operatorname{Ln}\left(P_{t}\right)}{\partial \theta} \\
& =-\frac{(\hat{\rho}(\hat{r})-(1-\varphi) \hat{r})\left(1-\frac{(\hat{g}+\pi)(1-\delta)}{\hat{\rho}(\hat{r})+(1-\varphi) \pi+\delta}\right)}{\theta \hat{\rho}(\hat{r})-\varphi \pi+(1-\theta)(1-\varphi) \hat{r}-\hat{g}+\tau+(\hat{g}+\pi)(1-\theta)(1-\delta) \frac{\hat{\rho}(\hat{r})-(1-\varphi) \hat{r}}{\hat{\rho}(\hat{r})+(1-\varphi) \pi+\delta}} .
\end{aligned}
$$

This equals zero when individuals discount at the market rate; that is, $\hat{\rho}(\hat{r})$ $=(1-\varphi) \hat{r}$. In other words, in the classic asset market approach to housing prices, down payment levels should not matter since home buyers discount at the market rate and are indifferent between paying cash and borrowing. An easier ability to borrow will not matter if people are not credit constrained.

Down payment levels do, however, start to matter if $\hat{\rho}(\hat{r})>(1-\varphi) \hat{r}$, meaning that the buyer would like to borrow more at the market rate. ${ }^{7}$ In a sense, the connection between down payment requirements and prices therefore becomes something of a test of whether individuals are credit constrained.

For example, table 7.2 shows the implied semielasticity if $\hat{g}=0.01, \pi=$ $0.032, \hat{r}=0.04, \delta=0.06, \varphi=0.25$, and $\tau=0.035$, and we vary the value of both $\theta$ and $\hat{\rho}$. If the private real discount rate is 0.09 or less (columns [1] and [2]), the implied elasticity is less than 0.77 even at very low down payments of 1 percent. If we choose very high real private discount rates of 0.15 or above (columns [3] and [4]), the implied semielasticity can climb to 2 if down payment requirements are very low. If the private discount rate is around 0.2 , a 5 percentage point change in the down payment requirement could create a price increase of as much as 10 percent. Given standard economists' beliefs about discount rates, we would expect to find a semielasticity between 0.4 and 0.8 . These effects do not change significantly when we allow for time-varying interest rates, and are not particularly sensitive to our other parameter values.

It is noteworthy that our model assumes that buyers are homogenous, so that the characteristics of the marginal buyers are unchanged when the down payment rate varies. If lower down payments allow less patient (or more overly optimistic) people to borrow, the impact on prices could be larger.

\subsubsection{Endogenous Housing Supply}

We now expand the model to incorporate worker heterogeneity and housing supply. In order for this expanded model to be tractable, we fix interest rates and eliminate mobility, so individuals live in their new homes permanently. We assume that there is a distribution of potential buyers, some of whom value the city more than others. In this case, we focus on overall housing demand instead of the own-rent arbitrage relationship. Ensuring

7. This requires that $\hat{\rho}(\hat{r})+(\delta-\varphi) \pi+\delta>\hat{g}(1-\delta)$, which we assume to hold. 
Price responsiveness to down payment requirements for varying private discount rates and down payment requirements

\begin{tabular}{lcccc}
\hline & $\hat{\rho}=0.06$ & $\hat{\rho}=0.09$ & $\hat{\rho}=0.15$ & $\hat{\rho}=0.20$ \\
\hline$\theta=0.2$ & 0.37 & 0.67 & 1.15 & 1.47 \\
$\theta=0.1$ & 0.38 & 0.72 & 1.3 & 1.73 \\
$\theta=0.05$ & 0.39 & 0.75 & 1.40 & 1.90 \\
$\theta=0.01$ & 0.40 & 0.77 & 1.48 & 2.05 \\
\hline
\end{tabular}

Notes: This table reports various values of the semielasticity of house prices with respect to down payment requirements, calculated using equation (4) in the text.

that workers are on the margin between owning and renting would not pin down the number of people in the area, which is needed to determine the housing demand. Thus we focus on the decision of whether to buy in the community or not, and do not focus on the unit's capital structure. In this framework, the net discounted cost of buying a house equals $(\theta+((1-\theta)$ $(1-\varphi) r) / \rho+\tau /(\rho-g)) P_{t}$, which reduces to $(1+\tau /(\rho-g)) P_{t}$ if $(1-\varphi) r=\rho$.

Each year, potential buyer $i$ receives a nominal dollar-denominated flow of utility from living in the house of $A_{t}(i)=(1+g)^{t} A(i)$, where $A(i)$ is the person-specific taste for the area. $A(i)$ has a Pareto distribution with parameter $1 / \gamma$, so there are $K A^{-1 / \gamma}$ buyers at time $t$ with valuations $A(i)$ that are greater than $A$. We also assume that only an independently distributed fraction $\alpha$ of buyers get approved for mortgages. As a result, if there are $N_{t}$ buyers at time $t$, then there will be $(\alpha K)^{\gamma} N_{t}^{-\gamma}$ approved buyers with values of $A(i)$ greater than $A$. Since the marginal buyer at time $t$ compares the discounted future value of housing flow utility to the present-value cost of buying, housing demand satisfies:

$$
\frac{(1+g)^{t}}{\rho-g}(\alpha K)^{\gamma} N_{t}^{-\gamma}=\left(\theta+\frac{(1-\theta)(1-\varphi) r}{\rho}+\frac{\tau}{\rho-g}\right) P_{t} .
$$

We can think of this as demand for the housing in a particular city, holding the options available elsewhere fixed. Alternatively, the value $A(i)$ can reflect the heterogeneous benefits from owning a home, if the utility from renting is held constant, or in principle, it might even reflect the benefits of moving into a housing unit at all, relative to cohabitating with a parent or friend.

Our second key assumption is that $I_{t}$ new homes are built each period and that the price of supplying new homes is $(1+g)^{t} c I_{t}^{\beta}$ (for $I_{t} \geq 1$ ). At each point in time, the number of homes being sold must equal $N_{t}$, so the housing supply equation is: $(1+g)^{t} c N_{t}^{\beta}=P_{t}$. The supply elasticity linking the number of homes supplied $\left(I_{t}\right)$ to the price, $\left(\partial \log \left(I_{t}\right)\right) /\left(\partial \log \left(P_{t}\right)\right)$, which we denote $\varepsilon_{P}^{D}$, equals $1 / \beta$. The demand elasticity linking the number of buyers to the price, $-\left(\partial \log \left(N_{t}\right)\right) /\left(\partial \log \left(P_{t}\right)\right)$, which we denote $\varepsilon_{P}^{D}$, will equal $1 / \gamma$.

Together, housing supply and demand yield: 


$$
\begin{gathered}
N_{t}=\left(\frac{(\alpha K)^{\gamma}}{c\left(\theta \rho+(1-\theta)(1-\varphi) r-g \theta-g \frac{(1-\theta)(1-\varphi) r}{\rho}+\tau\right)}\right), \text { and } \\
P_{t}=\frac{(1+g)^{t}\left(\alpha^{\beta} K^{\beta} c\right)^{\gamma /(\beta+\gamma)}}{\left(\theta \hat{\rho}(\hat{r})+(1-\theta)(1-\varphi) \hat{r}-\varphi \pi-\hat{g}+\tau-(\hat{g}+\pi)(1-\theta) \frac{(1-\phi) \hat{\rho}-\hat{\rho}(\hat{r})}{\hat{\rho})+\pi(1-\varphi)}\right)^{\beta /(\beta+\gamma)}} .
\end{gathered}
$$

These calculations somewhat alter the semielasticity of prices with respect to the interest rate, which now equals:

$$
\begin{aligned}
& \frac{\partial \operatorname{Ln}\left(P_{t}\right)}{\partial \hat{r}} \\
& =-\frac{\varepsilon_{P}^{D}}{\varepsilon_{P}^{D}+\varepsilon_{P}^{S}} \frac{\theta \hat{\rho}^{\prime}(\hat{r})+(1-\theta)(1-\varphi)-(\hat{g}+\pi)(1-\theta)(1-\varphi) \frac{\hat{\rho}(\hat{r})+\pi(1-\varphi))-\hat{\rho}^{\prime}(\hat{r})(\hat{r}+\pi)}{(\hat{\rho}(\hat{r})+\pi(1-\varphi))^{2}}}{\theta \hat{\rho}(\hat{r})+(1-\theta)(1-\varphi) \hat{r}-\varphi \pi-\hat{g}+\tau-(\hat{g}+\pi)(1-\theta) \frac{(1-\varphi) \hat{r}-\hat{\rho}(\hat{r})}{\hat{\rho}(\hat{r})+\pi(1-\varphi)}} .
\end{aligned}
$$

If $\hat{g}=0.01, \pi=0.032, \hat{r}=0.04, \theta=0.2, \tau=0.035, \varphi=0.25$, and $\hat{\rho}(\hat{r})=0.03$, then this expression becomes $-\varepsilon_{P}^{D} /\left(\varepsilon_{P}^{D}+\varepsilon_{P}^{S}\right)\left(17.5 \hat{\rho}^{\prime}(\hat{r})+2.8\right)$, which ranges from $-2.8 \varepsilon_{P}^{D} /\left(\varepsilon_{P}^{D}+\varepsilon_{P}^{S}\right)$ when $\hat{\rho}^{\prime}(\hat{r})=0$ to $-16 \varepsilon_{P}^{D} /\left(\varepsilon_{P}^{D}+\varepsilon_{P}^{S}\right)$ when $\hat{\rho}^{\prime}(\hat{r})=1-\varphi$. Personal discounting reduces interest rate sensitivity, but so does increasing supply elasticity. If $\varepsilon_{P}^{S}$ goes to zero when housing supply is perfectly inelastic, then the semielasticity goes to $-17.5 \hat{\rho}^{\prime}(\hat{r})-2.8$, while the semielasticity goes to zero when housing supply is perfectly elastic.

What is a reasonable value of $\varepsilon_{P}^{D} /\left(\varepsilon_{P}^{D}+\varepsilon_{P}^{S}\right)$ ? Saiz (2008) reports supply elasticities ranging from as low as 0.6 to as high as 5 across different markets; Topel and Rosen (1988) found a national supply elasticity of 2, and we use that as our core estimate.

The value of $\varepsilon_{P}^{D}$ is less clear since demand elasticities are typically estimated for the intensive margin (the amount of housing services each person consumes) rather than the extensive margin (the number of people in each city). The literature suggests the former elasticities are around 0.7 (Polinsky and Ellwood 1979). Saiz (2003) provides an alternative estimate. $\mathrm{He}$ found that a 9 percent increase in population, due to the plausibly exogenous Mariel boatlift, is associated with an 8 to 11 percent increase in rents in the short run. ${ }^{8}$ This shock would seem to be equivalent to an increase in the baseline population in our model, perhaps an increase in $K$, with fixed supply, so his estimates seem to imply that $\gamma$ is approximately one (we will use that value, but its imprecision for our purpose is acknowledged). ${ }^{9}$

If, for lack of a better alternative, we can take 1 as a measure of $\varepsilon_{P}^{D}$ and 2 as our measure of $\varepsilon_{P}^{S}$, then moving from a model with inelastic housing supply to elastic housing supply causes the interest rate-price relationship to fall

8. Saiz (2007) finds similar effects looking at increases in immigration throughout the country.

9. Saiz's experiment looks at a shock to the entire rental population, not to the flow of new buyers. We think that this suggests that his estimate is likely to be higher relative to a shock to the flow created by an increase in the approval rate, but he is looking at renters who may be somewhat more flexible in their preferences. 
Interest rate semielasticities with elastic housing supply

\begin{tabular}{lrrrrrr}
\hline & $(1)$ & $(2)$ & $(3)$ & $(4)$ & $(5)$ & $(6)$ \\
\hline Supply elasticity $\left(\varepsilon_{P}^{S}\right)$ & 0.5 & 0.5 & 2 & 2 & 4 & 4 \\
Discount rate linked? & Yes & No & Yes & No & Yes & No \\
Mobility $(\delta)$ & $6 \%$ & $6 \%$ & $6 \%$ & $6 \%$ & $6 \%$ & $6 \%$ \\
Down $(\theta)$ & $20 \%$ & $20 \%$ & $20 \%$ & $20 \%$ & $20 \%$ & $20 \%$ \\
Growth $(\hat{g})$ & $1 \%$ & $1 \%$ & $1 \%$ & $1 \%$ & $1 \%$ & $1 \%$ \\
Real interest rate & & & & & & \\
$\quad \hat{r}=0.03$ & -12.66 & -3.13 & -6.33 & -1.57 & -3.80 & -0.94 \\
$\hat{r}=0.04$ & -10.64 & -2.99 & -5.32 & -1.50 & -3.19 & -0.90 \\
$\hat{r}=0.05$ & -9.17 & -2.86 & -4.59 & -1.43 & -2.75 & -0.86 \\
$\hat{r}=0.06$ & -8.06 & -2.74 & -4.03 & -1.37 & -2.42 & -0.82 \\
$\hat{r}=0.07$ & -7.19 & -2.64 & -3.60 & -1.32 & -2.16 & -0.79 \\
\hline
\end{tabular}

Notes: This table reports calculated values of the semielasticity of house prices with respect to interest rates under various parameter assumptions. In the baseline scenario, shown in column (1), annual growth of rents and costs is $\hat{g}=0.01$, annual inflation is $\pi=0.032$, the marginal tax rate is $\varphi=0.25$, the down payment is $\theta=0.2$ of the purchase price, noninterest costs of homeownership are $\tau=0.035$, and annual mobility is $\delta=0.06$. When discount rates are linked to interest rates, $\hat{\rho}(\hat{r})=(1-\varphi) \hat{r}$, and $\hat{\rho}(\hat{r})=0.055$ otherwise. The semielasticity is evaluated at various initial real interest rates $\hat{r}$.

by two-thirds. Table 7.3 shows this effect for various values of the supply elasticity. Columns (1) and (2) show the interest rate semielasticity when $\varepsilon_{P}^{S}$ $=0.5$, columns ( 3 ) and (4) increase it to $\varepsilon_{P}^{S}=2$, and columns (5) and (6) show results with $\varepsilon_{P}^{S}=4$. Both when discount rates are linked to interest rates, as in the traditional model, and when they are separated, supply responses dramatically reduce the interest rate semielasticities. Supply elasticity thus provides us with yet another reason why the impact of interest rates on prices will be lower than in the canonical model.

\subsubsection{The Price Impact of Approval Rates}

This framework also enables us to consider more seriously the impact of higher approval rates, which in the model means a higher value of $\alpha$. If lower down payment requirements operate by enabling credit constrained people to borrow more, then the elasticity of prices with respect to approval rates will equal $1 /\left(\varepsilon_{P}^{D}+\varepsilon_{P}^{S}\right)$. The elasticity of units sold with respect to approval rates equals $\varepsilon_{P}^{S} /\left(\varepsilon_{P}^{D}+\varepsilon_{P}^{S}\right)$. If, for example, the approval rate across the entire population increased by 60 percent to 80 percent, the number of units sold would increase by 18 percent and prices would rise by 9 percent. The largest price effect would occur if $\varepsilon_{P}^{D}$ equals zero, and in that case, the impact on prices of approving an extra 20 percent of the population for mortgages would be 15 percent. In that case, the quantity increase would be exactly one-third.

If cheap credit acted primarily by enabling more people to buy homes, then theory and past work on housing gives us some idea of the kind of effect 
that such a shock to demand would be expected to have. Even a very large increase in approval rates, of 20 percentage points, would be predicted - by standard housing models - to have a relatively modest impact on long-run price, as long as supply remained modestly elastic. We will return to this in the impact section later.

A key assumption needed for these results is that increasing the approval rates essentially just shifts out the demand curve. It is certainly conceivable that higher approval rates particularly impact buyers with disproportionately high or low levels of demand. For example, if the poor are particularly likely to be on the approval margin, and if the poor have relatively less willingness to pay for housing, then the impact of higher approval rates would be lower than the effects discussed here. If the poor had high private discount rates and, hence, a lower willingness to pay for a house, then this would also make approval rates matter less than a standard shift out in the demand curve. Conversely, if higher approval rates disproportionately impact buyers with high demand, then the effect of approval rates can indeed be higher. As such, this becomes an empirical matter, but we do believe that theory suggests an approval rate price impact that is close to $1 /(3 \times$ Approval Rate).

\subsection{Empirical Analysis of Interest Rates and Housing Prices}

We begin the empirical section by examining the macroeconomic connection between interest rates and housing prices. We supplement this by looking at the connection between interest rates and construction activity. We also examine whether interest rate shocks have a larger impact in areas where housing supply is less elastic or where exogenous variables such as January temperature have long predicted positive housing price trends.

\subsubsection{National Time Series Data}

Real house prices are measured using the Federal Housing Finance Agency (FHFA) price index, deflated using the full Consumer Price Index (CPI-U, for all urban workers). Like the S\&P/Case-Shiller price indices, the FHFA series attempts to correct for the changing quality of houses being sold at any point in time by estimating price changes with repeat sales. ${ }^{10}$ The FHFA series begins in 1975, but we use data beginning in 1980 because the vast majority of metropolitan areas are covered on a consistent basis from that year onward. We use the FHFA instead of the S\&P/Case-Shiller series (which includes home sales financed using nonconventional loans), because the Case-Shiller data begin in 1987 and include only twenty metropolitan areas. Table 7.4 presents the summary statistics from this data, with table 7.5

10. The FHFA index supplements the repeat sales data with appraisal data, but there is also a purchase-only index (available for a shorter time window beginning in 1991 and a smaller number of areas). We have duplicated our results with that shorter time series and there is little change in the findings. 


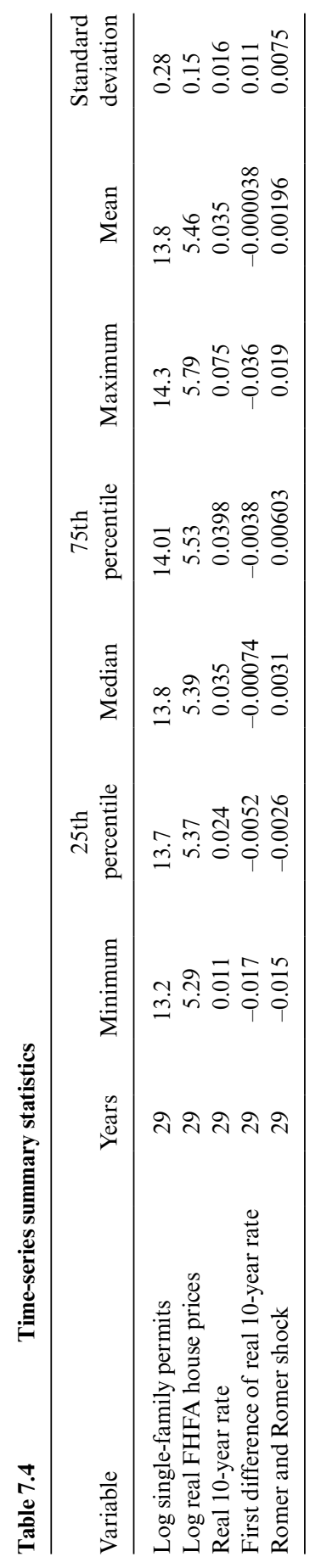




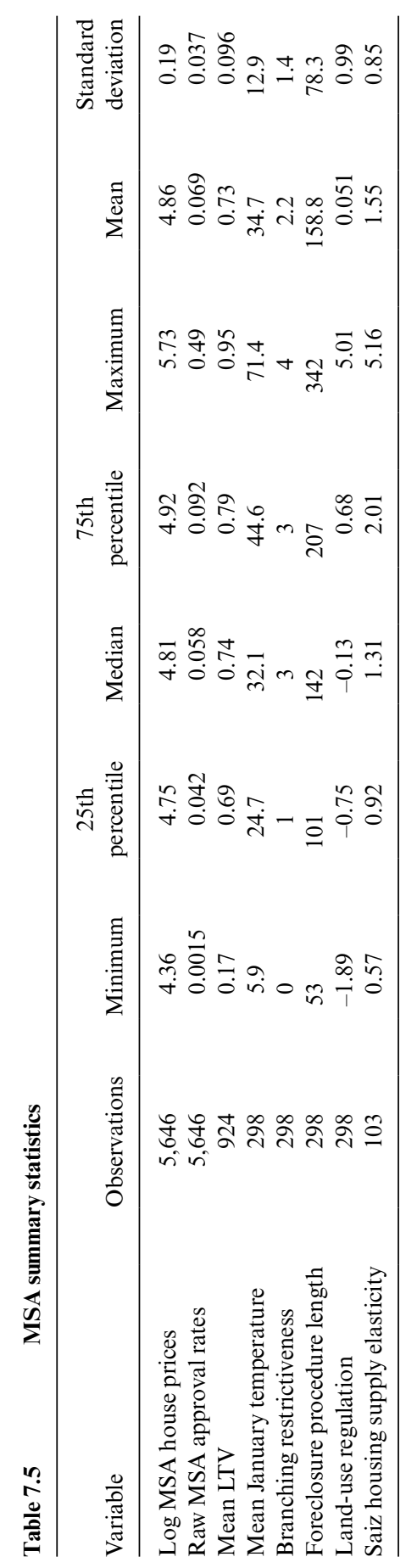




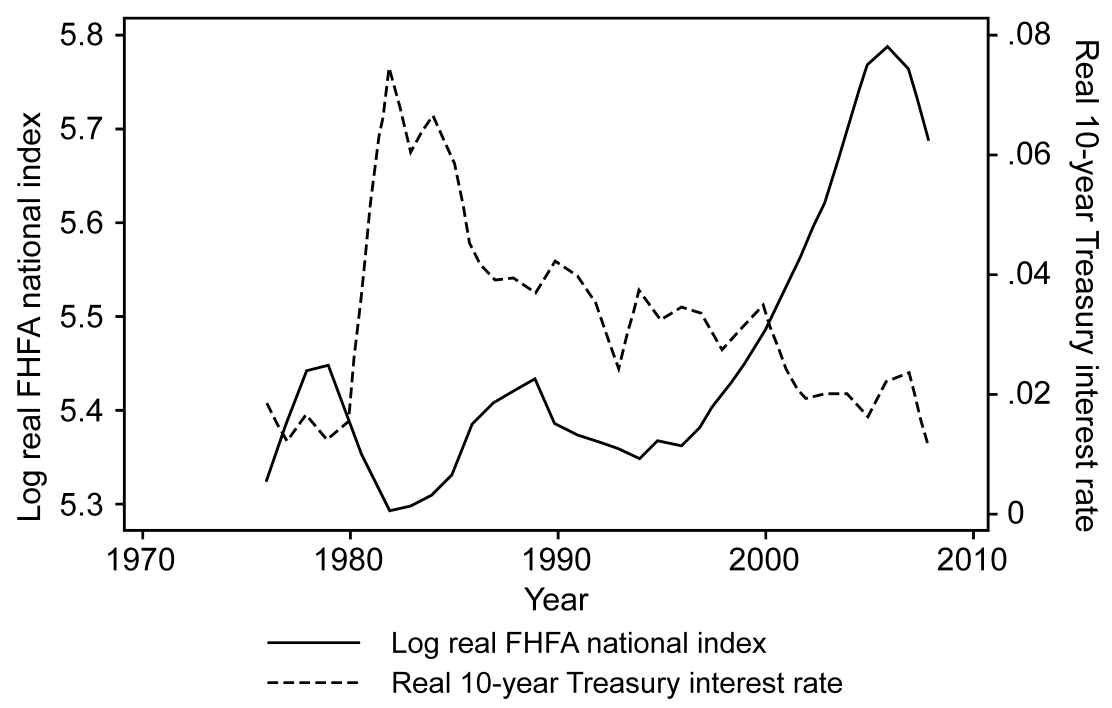

Fig. 7.1 Prices and interest rates

Sources: Federal Housing Finance Agency, Federal Reserve.

providing the analogous information on the other variables used in this section.

We use annual price data, even though higher frequency FHFA data is available, because the problems of intertemporal correlation of the error terms are reduced by using annual, rather than higher frequency data. Given the slow movement of housing prices, we believe that little is lost by focusing on year-to-year changes.

Real interest rates are constructed following the strategy outlined in HMS (2005). That is, we start with the ten-year Treasury bond rate and then correct for inflation with the Livingston Survey of inflation expectations. A long rate is used to approximate the duration of most mortgages. The Treasury rate rather than the actual mortgage rate is employed to reduce the feedback between events in the housing market and market rates. However, we have used alternative interest rates measures and found quite similar results. ${ }^{11}$

Figure 7.1 plots real interest rates and real housing prices over our full sample period from 1980 to 2008 . The strong negative trend in real interest

11. For example, Shiller $(2005,2006)$ uses a different and simpler real rate that is created by subtracting the actual inflation rate from the nominal Treasury yield. His methodology results in somewhat weaker correlations of house prices with interest rates than we report later. Hence, our method (really HMS's [2005] method) certainly is not biasing the results downward. Experimentation with other interest measures (e.g., based on longer or shorter rates and fixed inflation expectations) do not change the results in an economically meaningful way. In addition, experimentation with different lag structures on rates found that the contemporaneous relationship between rates and prices is the strongest. 
rates is clear, as real rates fall sharply from a peak of 7.5 percent in 1982 to 3.7 percent in 1989, before continuing downward at a more moderate pace. Ultimately, real ten-year rates hit a low of 1.6 percent in 2005 before rising slightly and then declining to 1.1 percent in 2008 as the Great Recession ensued. It is noteworthy that real house prices are flat over a significant part of this sample period, and the real FHFA index has virtually identical values in 1980 and 1997. Real house prices then appreciated by 49 percent from 1997 to the FHFA index peak in 2006, a period over which long real rates continued to fall.

Looking solely at this later time period, housing prices and interest rates seem to move in strongly opposite directions. This has lent support to some authors' claims of a strong connection between interest rates and housing prices (HMS 2005; Taylor 2009). However, over our nearly three decade sample period, the negative connection between interest rates and housing prices is much weaker. While real rates fell by 50 percent between 1982 and 1989 , real house prices increased by only 15 percent. In some years, such as 1993, real rates dropped drastically and real house price growth was flat. Real house prices actually fell the following year, so this is not an issue of a lagged effect. Prior to the most recent housing boom, even extreme changes in real rates had only a modest impact on prices.

Table 7.6 more formally documents this relationship by reporting the results of a series of regressions of the log FHFA price index on real tenyear interest rates and other covariates. To correct for serial correlation and heteroskedasticity, we employ the standard Newey and West (1987) correction. The simplest bivariate regression of log real prices on real rates suggests that a 100 basis point fall in real rates is associated with a $0.0682 \log$ point increase in house values (column [1]). ${ }^{12}$ This coefficient is closely in line with the relatively low semielasticities reported for calculations with elastic housing supply or with discount rates separated from interest rates. This finding suggests that a 1-standard deviation fall in real interest rates (1.57 percentage points in our time period, as reported in table 7.4) is unlikely to increase housing prices by much more than 10 percent.

Of course, one should be suspicious that this univariate relationship is biased because of reverse causality (e.g., lower housing prices causing a reduction in real rates) or because other variables may be correlated, or even cause, movements in both variables. For example, higher levels of economic productivity might push interest rates up and increase the demand for housing. If we include a simple time trend to correct for any bias from omitted variables that are trending in one direction and that are correlated with both interest rates and prices, we find that a 100 basis point decline in long

12. The model suggests that inflation will also impact prices, and we have also estimated specifications including the inflation rate, which did little but increase our standard errors. Given that actual inflation includes housing-related variables, this endogeneity led us to prefer the specifications without inflation. 


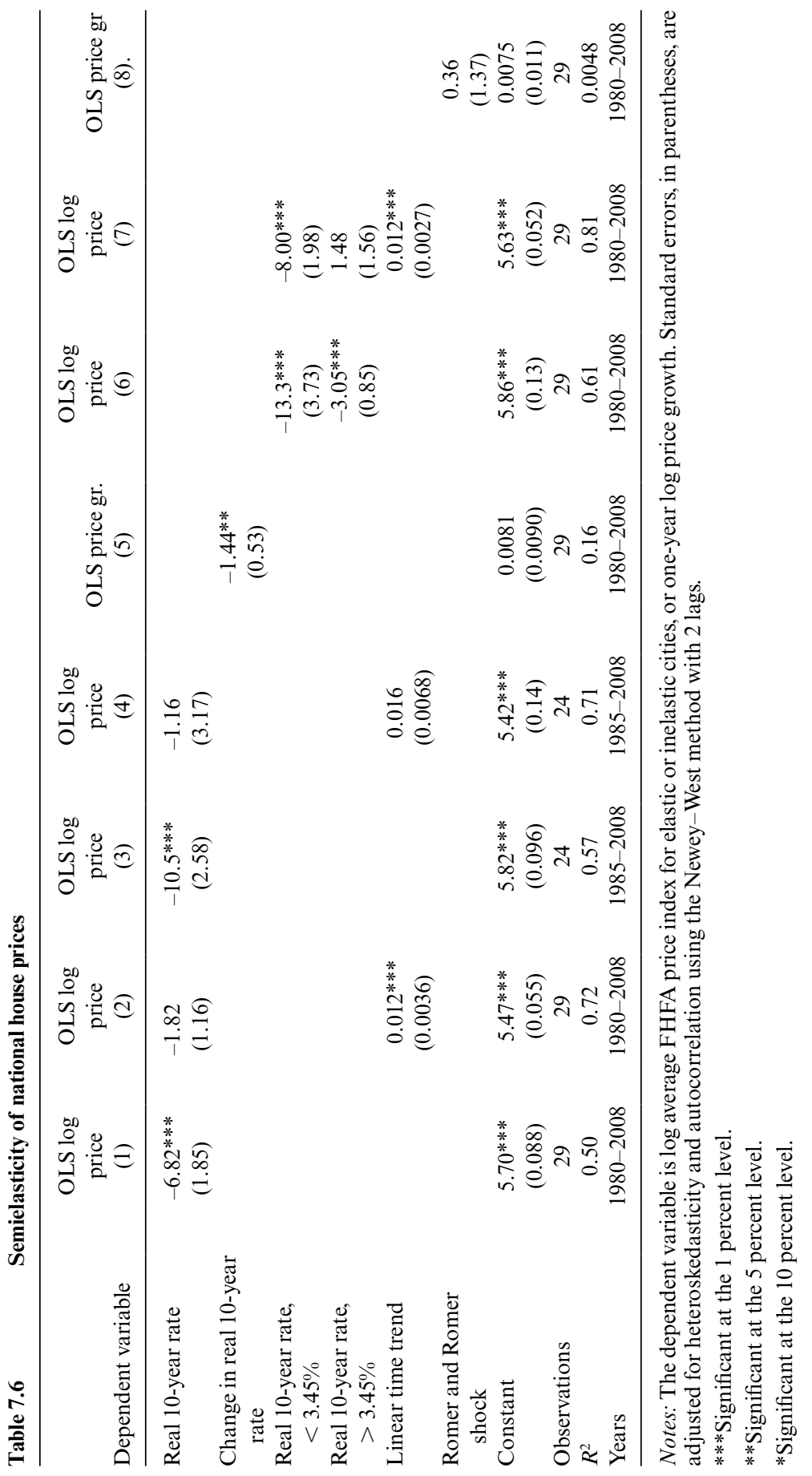


real rates now is associated with only a 1.82 percent increase in real house prices (table 7.6, column [2]). This effect is not significantly different from zero at standard confidence levels, but the standard error of the estimate is sufficiently tight to rule out anything more than a 4 percent impact on real prices from a 100 basis point decline in real rates, controlling for trend. ${ }^{13}$

These results are not materially affected even if the sample period is restricted to more recent years. That could be appropriate if one thought, for instance, that the early 1980s were sufficiently unusual, perhaps because of the volatility and possible mismeasurement of inflation expectations during those years. ${ }^{14}$ Column (3) of table 7.6 reports the bivariate relationship between house prices and interest rates when the sample period is restricted to 1985 to 2008 . The estimated impact of a 100 basis point fall in real rates increases to $0.105 \log$ points. However, this effect also is very sensitive to inclusion of a simple time trend. Column (4) shows that the estimated coefficient drops to -1.16 when the trend in real prices is controlled for.

These regressions effectively have presumed that house prices are stationary. If house prices have a unit root, our previous estimates would be invalid. To address this possibility, in column (5) we regress changes in the logarithm of real housing prices on changes in the real interest rate. In this case, the estimated coefficient is -1.44 , which is both small and fairly precisely estimated (standard error equal to 0.53 ). Hence, this specification also provides no support for a large impact of interest rates on house prices.

Poterba (1984), HMS (2005), and our model all suggest that changes in rates should have a larger impact on prices when rates themselves are lower. To test for this possibility, we estimate a piecewise linear spline function, with a break at the sample real interest rate median of 3.45 percent. Column (6)'s result shows that a 100 basis point decline in real interest rates is associated with a significantly higher 13.3 percent increase in real house prices when that change occurs within a low rate environment. However, this effect also is sensitive to including a time trend, as our seventh regression shows: detrended prices rise by only 8 percent when rates fall by 100 basis points from an already low level (i.e., from somewhere between 1.1 percent

13. Experimentation with other time varying controls such as real per capita GDP found that they generally lowered the estimated interest rate elasticity. Following Favilukis et al., chapter 6 in this volume, we also added measures of lending standards from Federal Reserve Bank's Senior Loan Officer Opinion Survey on Bank Lending Practices (SLOOS), which did not noticeably affect the interest rate estimates for the sample period for which the SLOOS data are available. Of course, there is the fear that these variables also are endogenous with respect to housing prices. Because adding these controls only reinforces the empirical point that the measured relationship between housing prices and interest rates is modest, we report only univariate and detrended results.

14. The median Livingston Survey inflation forecasts drop sharply from 9.9 percent to 5.8 percent between 1980 and 1984, which is the largest change (by far) over any five-year period in our sample. 
and 3.45 percent). ${ }^{15}$ Again, this estimate is well in line with our calculations when assuming elastic housing supply or separate interest rates and discount rates. The coefficient when rates are high is positive and indistinguishable from zero. An 8 percent price impact of a 100 basis point change in real rates certainly is not negligible, but as we shall see, it is far too small to explain much of the recent boom.

One problem throughout all of these estimates is that interest rates may themselves be endogenous to house prices. For example, heavy demand for housing itself could push interest rates up. A crash in housing prices, like that experienced after 2006, might cause the Federal Reserve to lower nominal rates. To address this issue, we tried to use the Romer and Romer (2004) measure of monetary policy shocks to instrument for interest rates. This variable captures the component of monetary policy decisions that cannot be explained by variables such as macroeconomic conditions and prior rates that are known before the Federal Reserve Board (FRB) meeting. Unfortunately, this measure is only weakly correlated with interest rates over the 1980 to 2008 time period (with an $F$-statistic of 1). As such, we do not use it as an instrument for rates, but simply include it as an alternative measure of credit availability. The final regression in column (8) of table 7.6 shows that this variable essentially is uncorrelated with housing prices. We interpret this result as supporting the view that that the weak connection between interest rates and housing prices observed in the data is unlikely to reflect reverse causality.

\subsubsection{Interest Rates and House Prices in Areas with Elastic and Inelastic Supply}

Table 7.7 reproduces key regressions from table 7.6 for different sets of cities in which housing is more or less elastically supplied. Following Glaeser, Gyourko, and Saiz (2008), we split the sample of metropolitan areas into three groups based on Saiz's (2008) measure of constraints on supply elasticity, which itself is based on area topography. Summary statistics for this measure, and other metropolitan statistical area (MSA)-specific data are presented in table 7.5. We compute a house price index for each tercile of supply elasticity, weighting MSAs by their population in 2000 .

The results in the first three columns, which are for the markets with the most elastic supplies of housing, indicate only a very modest housing price-interest rate relationship, as predicted by the model. The bivariate relationship reported in column (1) implies that a 100 basis point decline in real rates is associated with only 1.29 percent higher house prices (and the

15. The results throughout this table are similar when we use the log interest rate in place of the level, with the magnitude of the coefficient increasing from -6.82 to -7.12 in column (1) and from -1.82 to -1.94 when including a trend in column (2). Standard errors also increase very slightly. 


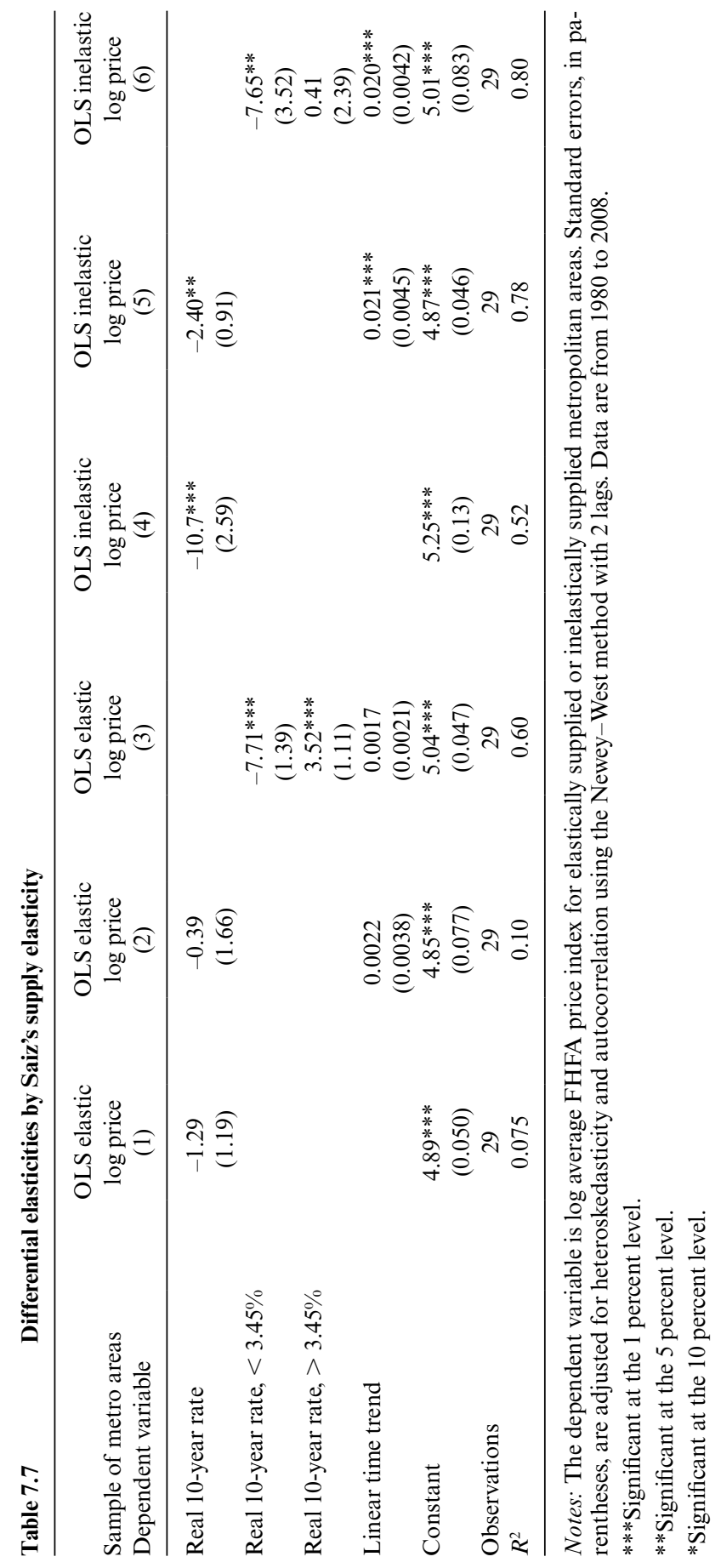


effect is not significantly different from zero). In column (2), we control for a trend in price and find an even smaller estimated impact of interest rates on prices in elastic markets. In column (3), we find that there is a significant effect when the rate occurs amidst relatively low interest rate environments. When we include a trend, a 100 basis point fall in real rates at these low levels is associated with nearly an 8 percent increase in prices. In this specification, the coefficient for changes in high interest rate environments is inexplicably positive.

Columns (4) through (6) report analogous results for the most inelastic markets. As basic price theory suggests should be the case in such markets, house prices are more sensitive to interest rates, as the simple bivariate relationship reports. Column (4) shows that a 100 basis point decline in real rates is associated with 10.7 percent higher house prices in these markets, but in column (5) we find that this coefficient drops by 75 percent when we control for a trend. Column (6) shows that most of this impact arises from rate changes in low interest rate environments. Still, the coefficient of -7.65 is modest compared to the volatility of price changes realized in inelastically supplied markets. Real prices more than doubled during the 1996 to 2006 boom in some of the coastal markets that have the most inelastic supplies of housing, so even large declines in interest rates cannot account for much of their price growth. ${ }^{16}$

\subsubsection{Summary and Conclusions}

It is hard to be overly confident about results drawn from thirty years of national data, but the data gives little support to the view that there is a large robust relationship between interest rates and prices. The strength of the empirical correlation between house prices and interest rates is much more consistent with the weaker relationship implied by our model when additional features are introduced and private discount rates need not equal market ones. Interest rates have very little ability to predict house prices independent of trend. A 100 basis point change in real rates is associated with no more than an 8 percent change (in the opposite direction) in detrended house prices, and that is only when the rate change is from a relatively low level.

In addition, there is no evidence that interest rates have a dramatic effect on quantities in the housing market. In appendix $\mathrm{C}$, we report the regression analogues to table 7.6, using construction, rather than housing prices, as the dependent variable. Those findings increase our confidence in the robustness of the price impacts. Construction statistics are thought to be better measured than house prices because a permit is required for each house. Hence, one well might be worried about measurement error being responsible for the weak estimated relationship between house prices and interest rates if

16. Results using the Wharton Residential Land Use Regulatory Index (WRLURI) reported in Gyourko, Saiz, and Summers (2008) yielded qualitatively and quantitatively similar results. 
Predicted interest rate impacts on price growth from data and model

\begin{tabular}{lrc}
\hline & $\mathrm{d} \ln (P) / \mathrm{d} r \times \Delta r=$ & Implied $\Delta P(\%)$ \\
\hline & A Overall, 1996-2006 & \\
\hline From model with $r=\rho+\pi$ & $-5.3 \times-1.2 \%=$ & 6.4 \\
From model with $r \neq \rho+\pi$ & $-1.0 \times-1.2 \%=$ & 1.2 \\
From data & $-6.8 \times-1.2 \%=$ & 8.2 \\
Actual price growth & & 42 \\
\hline
\end{tabular}

B Biggest change, 2000-2005

\begin{tabular}{lcc}
\hline From model with $r=\rho+\pi$ & $-5.3 \times-1.9 \%=$ & 10 \\
From model with $r \neq \rho+\pi$ & $-1.0 \times-1.9 \%=$ & 1.9 \\
From data & $-6.8 \times-1.9 \%=$ & 12.9 \\
Actual price growth & & 29 \\
\hline & C Crash, 2006-2008 & \\
\hline From model with $r=\rho+\pi$ & $-5.3 \times-1.1 \%=$ & 5.8 \\
From model with $r \neq \rho+\pi$ & $-1.0 \times-1.1 \%=$ & 1.1 \\
From data & $-6.8 \times-1.1 \%=$ & 7.5 \\
Actual price growth & & -11 \\
\hline
\end{tabular}

Notes: This table reports back-of-the-envelope calculations in which we attempt to explain observed house price growth using various estimates of the semielasticity of prices with respect to interest rates. Following Himmelberg, Mayer, and Sinai (2005), we examine a model where the interest rate is linked mechanically to the discount rate, by $r=\rho+\pi$. This generates the price semielasticity shown in row 1. Our more general model that allows $r$ to vary without changing $\rho$ is shown in row 2 . Finally, row 3 takes the semielasticity estimated empirically on data from 1980 to 2008. Reported actual price growth is in log points.

one found a very strong link between interest rates and construction. As appendix $\mathrm{C}$ shows, that is not the case across a variety of specifications.

How much of the total increase in prices can be explained by lower interest rates? Our approach to answering this question is to compare the actual price change over a particular time period, with the change in price implied by the coefficients suggested by the regressions reported above and by the model. In the latter case, the predicted impact is determined by multiplying by the changes in the potential explanatory variables over the same time period. We consider three separate time periods: 1996 to 2006 (the total boom), 2006 to 2008 (the bust), and a variable-specific subset of the boom that corresponds to the period of the largest change in the relevant credit market variable.

The first panel of table 7.8 shows our results using real interest rates and prices in the entire United States. We use -6.8 as our estimate of the empirical semielasticity of prices with respect to interest rates (from column [1] of table 7.6). This figure is the raw ordinary least squares coefficient and it sits comfortably within the estimates from the model as well. Between 1996 
and 2006, real prices using the FHFA index rose by $0.42 \log$ points. ${ }^{17}$ Over the same time period, real interest rates fell by 1.2 percentage points (or 120 basis points). As row three of the first panel indicates, this drop in real rates predicts a price increase of 8.2 percent, which is less than one-fifth of the total change over this period.

In order to compare these numbers with our model's ability to explain the boom, rows 1 and 2 show elasticities taken from the model. These elasticities come from computations where housing supply is somewhat elastic, the real rate is 0.04 , and we allow for mobility and a 20 percent down payment requirement. ${ }^{18}$ When prices are linked to interest rates, as in table 7.1 , the model elasticity is comparable to the empirical result, at -5.3 . Separating discounting from interest rates, we found a much smaller estimate of -1 , which has even less ability to explain the boom than the ordinary least squares (OLS) coefficient. We find larger elasticities if we reduce the down payments, increase the growth rate, or assume a lower starting interest rate, but even so, we would be hard-pressed to find plausible parameters that generate an elasticity large enough to explain a substantial fraction of the price appreciation over this period.

The period in which interest rates predict the largest rise in prices is between 2000 and 2005, when real rates fell by 190 basis points (middle panel of table 7.8). Using our semielasticity estimate of -6.8 , this change predicts a price rise of about $0.13 \log$ points. Yet over this period, real prices actually rose by $0.29 \log$ points, so even cherry-picking the time span, interest rate declines explain no more than 45 percent of the appreciation. Again, the results of our model—especially when $r \neq \rho+\pi$-predict smaller price increases than the OLS coefficient.

During the 2006 to 2008 bust, real interest rates continued to fall-by 110 basis points. Of course, that implies that prices should have risen - by 7.5 percent, given our elasticity estimate — as reported in the bottom panel of table 7.8. During this period prices actually fell by about 11 percent, so it is quite clear that interest rates cannot explain the bust. Because our model also predicts a negative relationship between house prices and interest rates, they also get the direction of price change wrong, but now the prediction error is smaller in magnitude.

Table 7.9 reports analogous results focusing on inelastically supplied metropolitan areas, defined as the lowest tercile according to Saiz's (2008) measure of supply elasticity. In this case, we again use the raw OLS estimated coefficient of -10.7 (from column [4] of table 7.7) as our empirical semielasticity. As the top panel shows, the 1.2 percentage point drop in interest rates

17. This is equivalent to the 53 percent change noted in the introduction. We work with log points here because that is the metric by which our model predictions are computed.

18. Except for allowing for a positive supply elasticity, the assumptions are the same as those in column (4) of tables 7.1 and 7.2. 
Table 7.9

Predicted interest rate impact on price growth in supplyconstrained MSAs

\begin{tabular}{lrc}
\hline & $\mathrm{d} \ln (P) / \mathrm{d} r \times \Delta r=$ & Implied $\Delta P(\%)$ \\
\hline & A Overall, 1996-2006 & \\
\hline From model with $r=\rho+\pi$ & $-16 \times-1.2 \%=$ & 19.2 \\
From model with $r \neq \rho+\pi$ & $-7.5 \times-1.2 \%=$ & 9 \\
From data & $-10.7 \times-1.2 \%=$ & 12.8 \\
Actual price growth & & 63 \\
\hline
\end{tabular}

B Biggest change, 2000-2005

\begin{tabular}{lrc}
\hline From model with $r=\rho+\pi$ & $-16 \times-1.9 \%=$ & 30.4 \\
From model with $r \neq \rho+\pi$ & $-7.5 \times-1.9 \%=$ & 14.2 \\
From data & $-10.7 \times-1.9 \%=$ & 20.3 \\
Actual price growth & & 42 \\
\hline & $\mathrm{C}$ Crash, 2006-2008 & \\
\hline From model with $r=\rho+\pi$ & $-16 \times-1.1 \%=$ & 17.6 \\
From model with $r \neq \rho+\pi$ & $-7.5 \times-1.1 \%=$ & 8.3 \\
From data & $-10.7 \times-1.1 \%=$ & 11.8 \\
Actual price growth & & -16 \\
\hline
\end{tabular}

Notes: This table reports back-of-the-envelope calculations in which we attempt to explain observed house price growth using various estimates of the semielasticity of prices with respect to interest rates. Following Himmelberg, Mayer, and Sinai (2005), we examine a model where the interest rate is linked mechanically to the discount rate, by $r=\rho+\pi$. This generates the price semielasticity shown in row 1. Our more general model that allows $r$ to vary without changing $\rho$ is shown in row 2 . Finally, row 3 takes the semielasticity estimated empirically on data from 1980 to 2008. Reported actual price growth is in log points.

between 1996 and 2006 predicts about a $0.13 \log$ point increase in housing prices, while actual house prices for this group of markets rose by a much larger $0.63 \log$ points.

Our model can account for even less of the very high price appreciation experienced in inelastically supplied markets. Here we assume fixed supply and use the same parameter values as those for the calculations reported in column (1) of tables 7.1 and 7.2. These computations assume 1 percent annual real growth, a 20 percent down payment requirement, and 6 percent annual mobility. We take the elasticities computed at a real rate of 4 percent, both in the case of linked discount rates and a fixed, separate discount rate. In the former case the elasticity is -16 , which predicts a $0.19 \log$ point price increase, and in the latter case the elasticity of -7.5 predicts appreciation of only $0.09 \log$ points (see the top panel of table 7.9).

The 190 basis interest rate drop between 2000 and 2005 predicts over a 0.2 log point price bump for this group, which again falls considerably short of the actual $0.42 \log$ point increase in housing prices that was experienced by these inelastically supplied markets over these years (middle panel of table 
7.9). During this specially chosen period, the predicted impact of interest rates on prices was considerable, but it still is not enough to explain more than half of the true price gain in these markets under our new assumptions. The traditional model with discount rates linked to interest rates does somewhat better here, predicting three-quarters of the true price growth, but this relies on an elasticity two-thirds larger than our empirical estimate. And as the bottom panel shows once again for the bust in prices between 2006 and 2008 , interest rates have no ability to explain the price drop because their predicted impact is to raise prices during the period of the housing bust.

\subsection{The Impact of Approval Rates on Housing Demand and Prices}

Interest rates were not the only thing about credit markets that was changing, especially during the boom, so perhaps other factors were more important and can more fully account for what went on in housing markets. To investigate those possibilities, we now turn to our other credit market variables: approval rates and average loan-to-value ratios. In doing so, we can use variation across metropolitan areas by year, but we still face two principal problems. First, there is a major endogeneity concern because housing market conditions seem likely to influence bank policies. Second, empirical measures of credit availability are likely to be confounded by the changing characteristics of mortgage applicants. While we try to deal with each concern, they remain so considerable that we conclude that our results must be treated as being suggestive rather than definitive.

\subsubsection{Mortgage Applications and Approval Rates}

Let $N_{B}$ denote the number of people who would like to buy a house if they could get credit, which in the model equals $N_{t} / \alpha$ or $K\left((1+g)^{t} /\left(\rho_{t}-g\right) /\right.$ $\left.\left(\theta+((1-\theta)(1-\varphi) r) / \rho_{t}+\tau /\left(\rho_{t}-g\right)\right) P_{t}\right)^{1 / \gamma}$. A fraction $\alpha$ of this group will be able to get credit and purchase a home. We assume that all people who want a home and can get a loan apply for the mortgage. We assume that there is some uncertainty about who can get a loan, so an additional share $\varphi$ of the ineligible population wants to buy a home and applies for a loan. Thus an extra fraction $(1-\alpha) \varphi$ of the entire population also applies for a loan, in addition to the $\alpha$ who will actually receive loans. The parameter $\varphi$ might be interpreted as reflecting the level of optimism that high-risk buyers have about getting a loan.

The approval rate observed in real data (i.e., the proportion of applications that lead to a loan) does not equal $\alpha$ - the unconditional probability of getting a loan - but instead equals $\alpha /(\alpha+(1-\alpha) \varphi)$, which is greater than $\alpha$. If we compare approval rates over time, it is quite possible for $\alpha$ to rise and for the measured approval rate to decline if $\varphi$, which reflects optimism about getting a loan, also rises. For example, if $\alpha$ was initially 0.5 and $\varphi$ was initially 0.25 , then the measured approval rate would be 0.8 . If $\alpha$ then rose 
to 0.6 and $\varphi$ rose to 0.5 , then the measured approval rate would decline to 0.75 . A significant increase in approval would look like a decline in the actual approval rate if the share of high-risk individuals aggressively applying for loans also rose. Since a loosening of credit might well lead many marginal applicants to apply for loans, this problem could be quite severe.

Despite this, we will use the raw approval rate, and the approval rate correcting for individual characteristics, as our first measure of changes in the lending environment. We are essentially assuming that $\varphi$ is fixed. In this case, the measured approval rate will show the correct direction of change, and if $\hat{a}$ denotes the measured approval rate then the real approval rate $\alpha$ will equal $\varphi \hat{a} /(1-\hat{a}(1-\varphi))$, which we report for a range of values of $\varphi$. While this provides a useful benchmark, we believe that it is still likely to substantially mismeasure the changes in the approval rate.

Our second approach is to assume that the value of $\varphi$ increased over the boom. We make what we consider a reasonably extreme assumption; namely, that in $1996, \varphi$ equals 0.5 and that it increased by 0.025 per year for the next decade, reaching 0.75 by 2006 . This would represent a 50 percent increase in the share of the people who will not get a loan, but who apply for a loan over this period.

Our third approach is to use the increase in the number of people who get loans, which should equal $\alpha^{\prime} N_{B}^{\prime} / \alpha N_{B}$, where $\alpha^{\prime}$ and $N_{B}^{\prime}$ reflect the ex post values of these variables. Since the boom surely also led to an increase in the number of people who wanted to buy a home, we must have some means of correcting for $N_{B}^{\prime} / N_{B}$. Unfortunately, we know of no good way of performing this correction. Our first approach is to assume that the growth rate of the number of buyers is three-quarters the growth rate of the number of accepted applications. Our second approach is to assume that the growth rate of interested buyers is one-half the growth rate in the number of accepted applications.

\subsubsection{Measuring the Change in Approval Rates}

In order to measure the availability of mortgages during the past two decades, we use data released by the Federal Financial Institutions Examination Council under the Home Mortgage Disclosure Act (HMDA). These data provide a relatively complete universe (203,511,952 observations) of all US mortgage applications between 1990 and 2008. ${ }^{19}$

19. We use the 298 metropolitan areas included in these files in our subsequent empirical analysis. Applicants are dropped if they have an explicit federal guarantee from the Federal Housing Authority (FHA), Veterans Affairs (VA), Farm Service Agency (FSA), or Rural Housing Services (RHS), if they withdrew the application (following Munnell et al. 1996), or if they have invalid geographic coding. In addition, we use data on all applications, whether for purchase or refinance. Restricting the analysis to purchases does not change our conclusions (reported later) in any material way. More specifically, there is no permutation of the data we could find that suggested this variable could account for the bulk of the boom in house prices. 


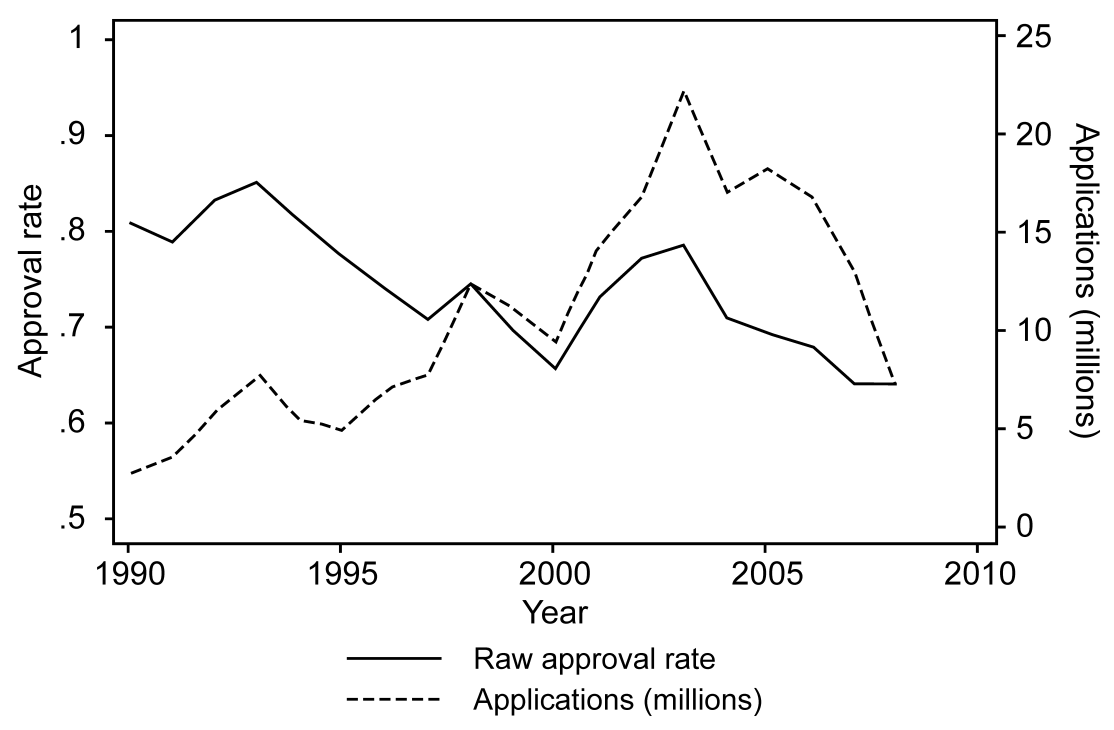

Fig. 7.2 Applications and approval rate

Source: HMDA data released by the Federal Financial Institutions Examination Council.

Figure 7.2 shows the number of applications in our HMDA sample in each year along with the raw approval rate. The number of applications skyrockets over the period from 1995 to 2005 , nearly tripling over the decade. The approval rate, on the other hand, is reasonably constant, though declining slightly, over this period. It falls from 78 percent in 1995 to 66 percent in 2000 , and then rapidly jumps back to 78 percent by 2002 . It increases another percentage point in 2003 before falling back to 70 percent by 2005 and then declining to 65 percent in 2007 and $2008 .^{20}$

The lack of an overall trend in approval rates as the housing boom intensified is somewhat surprising given that other work finds a substantial easing of credit for marginal borrowers during this period (Keys et al. 2010). On the other hand, Greenspan (2010) reports that issuances of adjustable-rate mortgages also peaked in 2004, and Bubb and Kaufman (2009) question whether increased mortgage securitization actually led underwriting standards to deteriorate.

The large expansion in the number of applications raises the possibility that there was a substantial shift in the composition of mortgage applicants: an increase in the parameter $\varphi$ discussed earlier. A number of the individual characteristics included in the HMDA data do change during the sample period. For example, figure 7.3 shows the increasing share of applications 


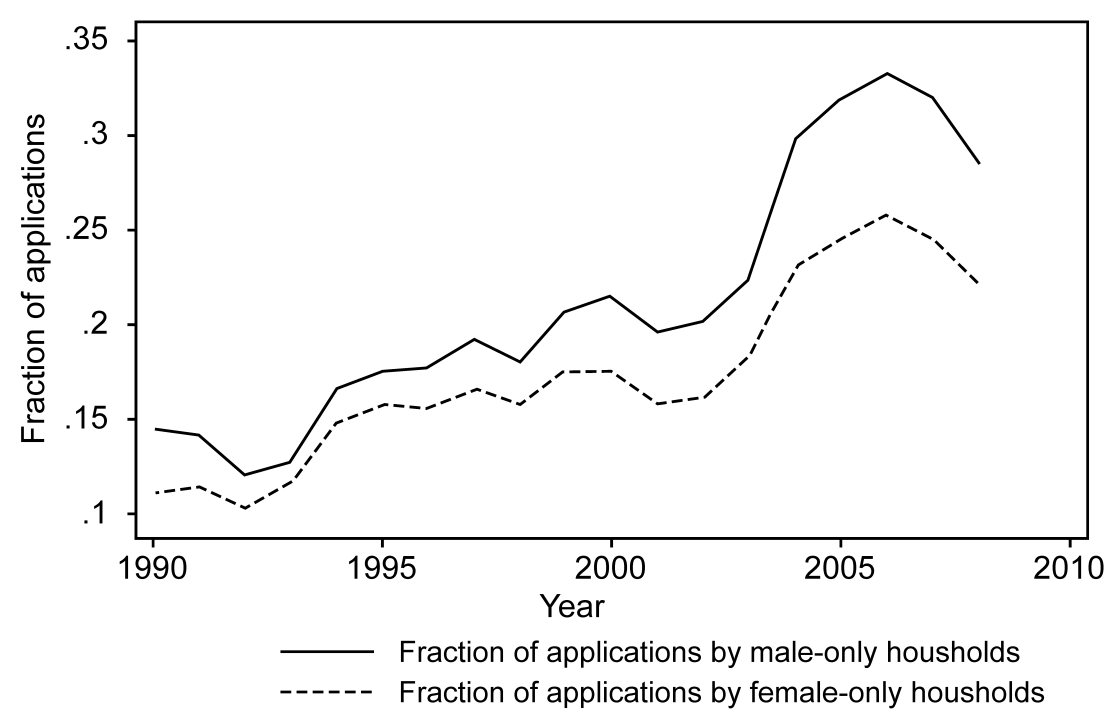

Fig. 7.3 Distribution of applications

Source: HMDA data released by the Federal Financial Institutions Examination Council.

made by single male and single female applicants, typically seen as riskier lending prospects than families. One important question is whether the rise in the number of applicants is itself a reflection of easier lending standards or whether it reflects a more general enthusiasm for the market on the part of potential buyers (or both). Figure 7.4 shows the changing approval rates for the three types of applications. The three series mirror each other, showing a decline until the year 2000, a rise between 2000 and 2004, and a decline after that period. This suggests that the 2000 to 2004 increase in applicants could be driven by increasing approval rates, but there is less evidence to support such a connection outside of those years.

In order to accurately measure credit availability, we aim to estimate the changing approval rate for a marginal buyer of constant attributes. We attempt to correct for differential selection of mortgage applicants by controlling for observable individual characteristics. In order to estimate the ease of a given person getting a loan in each metropolitan area in each year, we run the following regression for each year for which we have data:

$$
\begin{aligned}
\text { Approval }_{i, j}= & \zeta_{1} \text { Individual Controls }_{i, j} \\
& +\zeta_{2} \text { Metro Area-Year Fixed Effects }_{i}+u_{i, j} .
\end{aligned}
$$

The dependent variable here, Approval ${ }_{i, j}$, is a dummy indicating whether the application of individual $i$ in metropolitan area $j$ was approved (a value of 1 indicates approval; 0 indicates rejection). Appendix A reports the coefficients on applicant characteristics from one year's data, which include race, sex, 


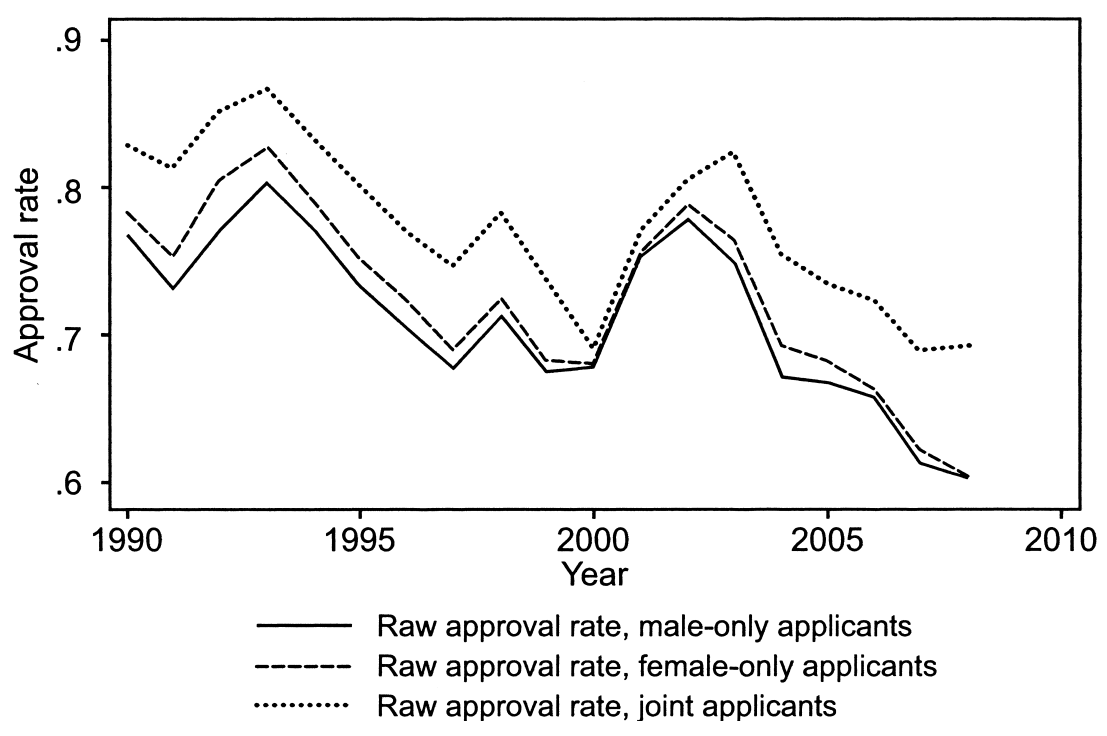

Fig. 7.4 Approval rates by demographic group

Source: HMDA data released by the Federal Financial Institutions Examination Council.

and a nonparametric specification of income. We also control for interactions between sex and income in this vector. We include metropolitan area fixed effects in each regression. They are the focus of this particular effort, as the year-by-metropolitan area-specific approval rates (controlling for applicant differences as best we can) are used to estimate the impact of changing approval rates over time on house prices. We estimate such rates for the nineteen years of HMDA data that are available, and for 298 metropolitan areas.

Our second approach is more nonparametric. We estimate an approval rate in each year and each metropolitan area for each population subgroup, denoted Approval ${ }_{\text {group, }, \mathrm{t},}$ and then form a predicted approval rate using the population weights of applications as of 1996. This procedure is meant to hold the characteristics of potential borrowers fixed and let metropolitan area level approval rates change only because of changing approval rates within groups. The solid and plain dashed lines in figure 7.5 shows the time series pattern of national approval rates for the country as a whole, using these two methods of correcting the approval rate. There appears to be little upward trend in the demographics-corrected approval rates; however, we try to measure them.

Table 7.10 provides us with six different estimates of the changes in the approval rate. The first column shows how the raw approval rates change over time, which would be the actual approval rate if $\varphi=1$. The second column shows the same pattern if $\varphi=0.5$ throughout the period. This 


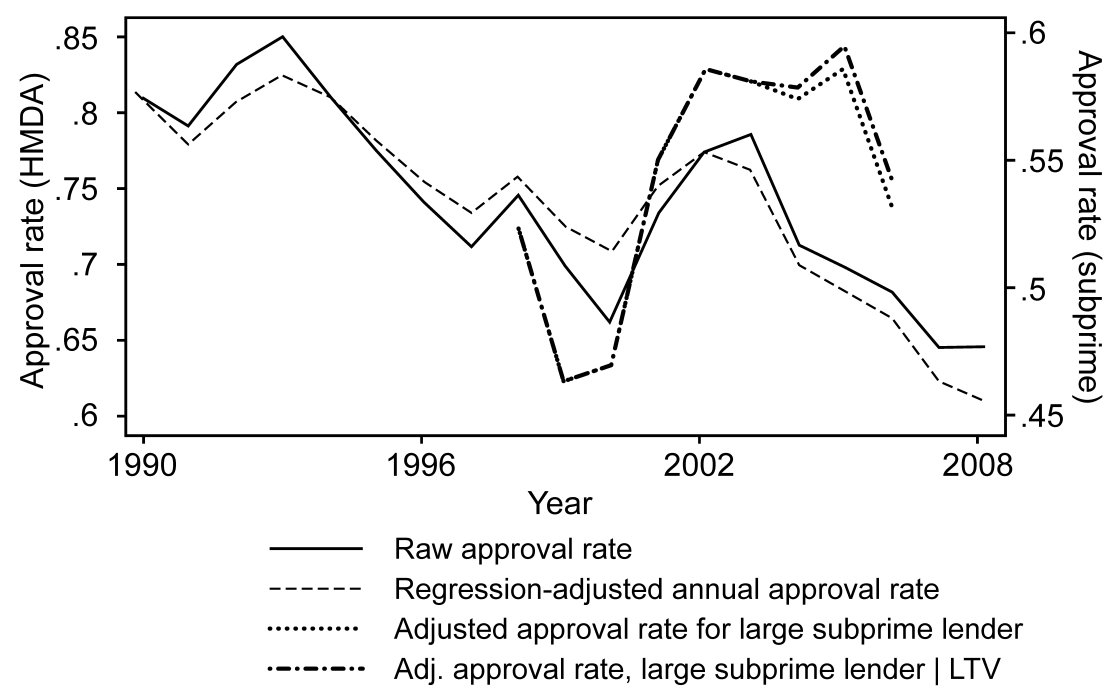

Fig. 7.5 Measures of mortgage approval rates

Sources: HMDA data released by the Federal Financial Institutions Examination Council and applications to a large subprime lender from Amit Seru.

correction does reduce the implied approval rate but it does not materially change the time-series pattern of approval rates.

The third column shows the implied approval rate if $\varphi=0.5$ until 1996, then increases by 0.025 per year until 2006, and then declined by 0.025 per year after that. This change is relatively arbitrary, but it shows what a significant increase in applications by unqualified would-be buyers will do to the implied underlying approval rate. With this assumption, we estimate that the underlying approval rate increased by 14 percentage points from 63.5 percent in 1996 to 78.2 percent in 2004, and 10 percentage points from 1996 to 2006.

The fourth column infers the approval rates from the ratio of accepted mortgages in a given year to the ratio of accepted mortgages in 2005, the year of the largest number of accepted mortgage applications. Specifically, as Accepted ${ }_{t} /$ Accepted $_{2005}=\alpha_{t} / \alpha_{2005} N_{B, t} / N_{B, 2005}$, we assume that the change in the number of buyers $N_{B, l} / N_{B, 2005}$ equals (Accepted $/$ Accepted $\left._{2005}\right)^{z}$, where $z$ is less than one, so $\alpha_{t}=\left(\text { Accepted }_{t} / \text { Accepted }_{2005}\right)^{1-z} \alpha_{2005} \cdot{ }^{21}$ We show the results where $z=0.75$ in column (4), which means that approximately three-fourths of the growth in accepted applications is due to growth in demand. Results for $z=0.5$ are reported in column (5), which means that approximately onehalf of the growth in accepted applications is due to growth in demand.

21. We think of this approach as partitioning the $\log \left(\right.$ Accepted $_{t} /$ Accepted $\left._{2005}\right)$ into $\log \left(\alpha_{t} / \alpha_{2005}\right)+\log \left(N_{B, t} / N_{B, 2005}\right)$, and assuming that $\log \left(N_{B, t} / N_{B, 2005}\right)$ is responsible for either three-quarters or one-half of the growth in acceptances. 


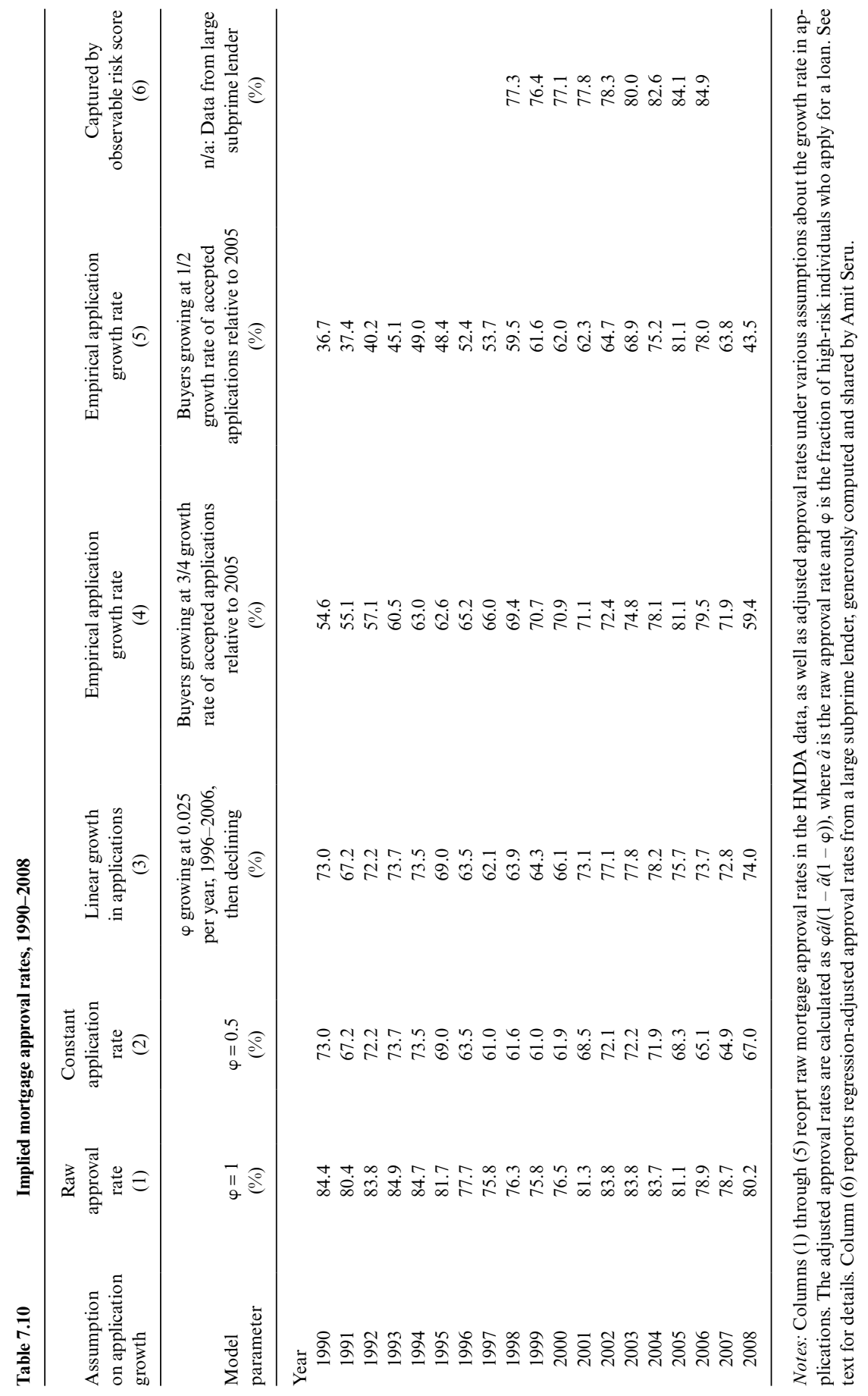


Column (4) shows a growth in the implied acceptance rate from 65.2 percent in 1996 to 79.5 percent in 2006. Column (5) shows a growth in the implied acceptance rate from 52.4 percent in 1996 to 78.0 percent. To our eyes, 52.4 percent seems like a low number given that the home ownership rate was 65 percent in that time period. Clearly more than 52.4 percent of the population was able to buy a home at some point in their lives.

Using richer data from a different market segment, namely subprime borrowers, reveals a somewhat clearer pattern. Approval rates for mortgage applications submitted to a large subprime lender, adjusted for a richer set of borrower characteristics, are shown in column (6), and in the remaining lines of figure 7.5. ${ }^{22}$ The dashed-dotted lines show an increase of 13.3 percentage points in this lender's adjusted approval rate from 1999 to 2005, and that controlling for the application's loan-to-value ratio reduces the gain slightly to 12.5 percentage points.

While the time series of these approval rates look somewhat more promising as an explanation for the housing boom, the magnitudes of changes remain relatively modest. Even for the subprime population, the measured increase in credit availability is well within the range of the HMDA-derived estimates presented in table 7.10.

\subsubsection{The Impact of Approval Rates on Price}

The model predicted that a permanent change in approval rates influences prices according to the formula $\log \left(P^{\prime} / P\right)=1 /\left(\varepsilon_{P}^{I}+\varepsilon_{P}^{N}\right) \log \left(\alpha^{\prime} / \alpha\right)$. As dicussed earlier, this implies an elasticity of about $1 / 3$, given standard supply and demand elasticities. While we may trust the theory more than the data, in this section we also estimate an elasticity of prices with respect to measured approval rates.

Using metropolitan area-level data pooled across years, we can now examine the impact of approval rates on the FHFA local house price index. In equation (10), we regress the log price index on our measures of adjusted approval rates taken from the $\zeta_{2}$ vector and, hence, holding borrower characteristics constant.

$$
\begin{aligned}
\log \left(\text { Index }_{j, t}\right)= & \Omega_{1} \text { Approval Rate }_{j, t} \\
& +\Omega_{2} \text { MSA }_{j}+\Omega_{3} \text { Year }_{t}+\Omega_{4} \text { Controls }_{j, t}+\varepsilon_{j, t} .
\end{aligned}
$$

Approval Rate ${ }_{j, t}$ is the estimated rate for metropolitan area $j$ in year $t$, controlling for metropolitan area and year fixed effects. The other controls are interactions between a time trend and (a) mean January temperature and (b) the Wharton Residential Land Use Regulatory Index (WRLURI). The

22. We are deeply indebted to Amit Seru for computing and sharing these adjusted approval rates and adjusted loan-to-value ratios from his data on mortgage applications at a large subprime lender. These regressions control for borrower's sex, marital status, FICO score, presence of income documentation, self-employment status, and debt-to-income ratio. 
latter measures the degree of supply restrictiveness in the area (Gyourko, Saiz, and Summers 2008). ${ }^{23}$

Results for different specifications of equation (10) are reported in table 7.11. The first regression finds that as raw approval rates increase by 1 percent, prices rise by $0.0018 \log$ points, holding metropolitan area and year fixed. While the individual controls available are quite limited, the year effects help account for some important changes in applicant characteristics over the boom (see chapter 4 ). This coefficient is statistically significant and shows that prices and approval rates moved together positively. The second regression shows the regression-corrected approval rate, with standard errors corrected for estimation error in the approval rate by bootstrapping. ${ }^{24}$ In this case, the impact of a 1 percent approval rate increase is to increase prices by $0.0021 \mathrm{log}$ points. Our third regression uses approval rates based on 1999 applicant weights, as explained before. In this case, the coefficient falls to 0.14 . In both cases, correcting for these group changes causes the estimated effect on prices to fall rather than rise. In regression (4), we control for state-year fixed effects so that all our identifying variation comes from differences across metropolitan areas within a given state for a given year. The estimated coefficient is stable at 0.20.

There are two potential problems with these coefficients. First, we are using measured approval rates, which do not reflect the relevant underlying approval rate unless $\varphi$, the rate of optimistic application, equals one. This mismeasurement will not be classical measurement error, and the problem will get more severe if $\varphi$ differs from place to place and is correlated with the true underlying approval rate. ${ }^{25}$ Second, the approval rate may be itself endogenous with respect to price.

If $\varphi=1$, then these estimated effects are somewhat smaller than our theoretical predictions. The model predicted a semielasticity of $1 /(3 \times$ Approval Rate). If the approval rate is 0.8 , then this predicts a semielasticity of 0.42 , which is somewhat higher than the effect estimated here, but still reasonably

23. There are few variables that are available on an annual basis at the metropolitan level, and those that are, such as employment rates, seem likely to be endogenous with respect to the housing market.

24. We use the estimated MSA fixed effects and their covariance matrix from the annual implementations of regression (9) to draw 100 realizations of the approval rates used in regression (10). Note that this ignores the covariance between annual fixed effects for a given MSA, but since we have 298 metropolitan areas and nineteen years of data, incorporating the cross-MSA covariances is more conservative. Furthermore, we cluster our standard errors in regression (10) by MSA. Following Mas and Moretti (2009, appendix), we add the estimated variance of $\widehat{\Omega_{1}}$ to the cross-equation variance of $\widehat{\Omega_{1}}$ to determine our composite bootstrap standard error.

25 . To see the effect of mismeasurement, follow the model that tells us that the linear approximation for the $\operatorname{logarithm}$ of prices is that $\log (P)=\log (\bar{P})+1 /\left(\varepsilon_{P}^{I}+\varepsilon_{P}^{N}\right) \alpha / \bar{\alpha}$ and the measured approval rate is equal to $\widehat{\operatorname{App}}+\left(\varphi(\alpha-\bar{\alpha}) /(\bar{\alpha}+(1-\bar{\alpha}) \varphi)^{2}\right.$, where $\bar{P}, \widehat{\mathrm{App}}$, and $\bar{\alpha}$ reflect the average values of price, measured approval, and true approval. The regression coefficient is therefore equal to $1 /\left(\varepsilon_{P}^{I}+\varepsilon_{P}^{N}\right)$ divided by $\varphi /(\bar{\alpha}+(1-\bar{\alpha}) \varphi)^{2}$. 


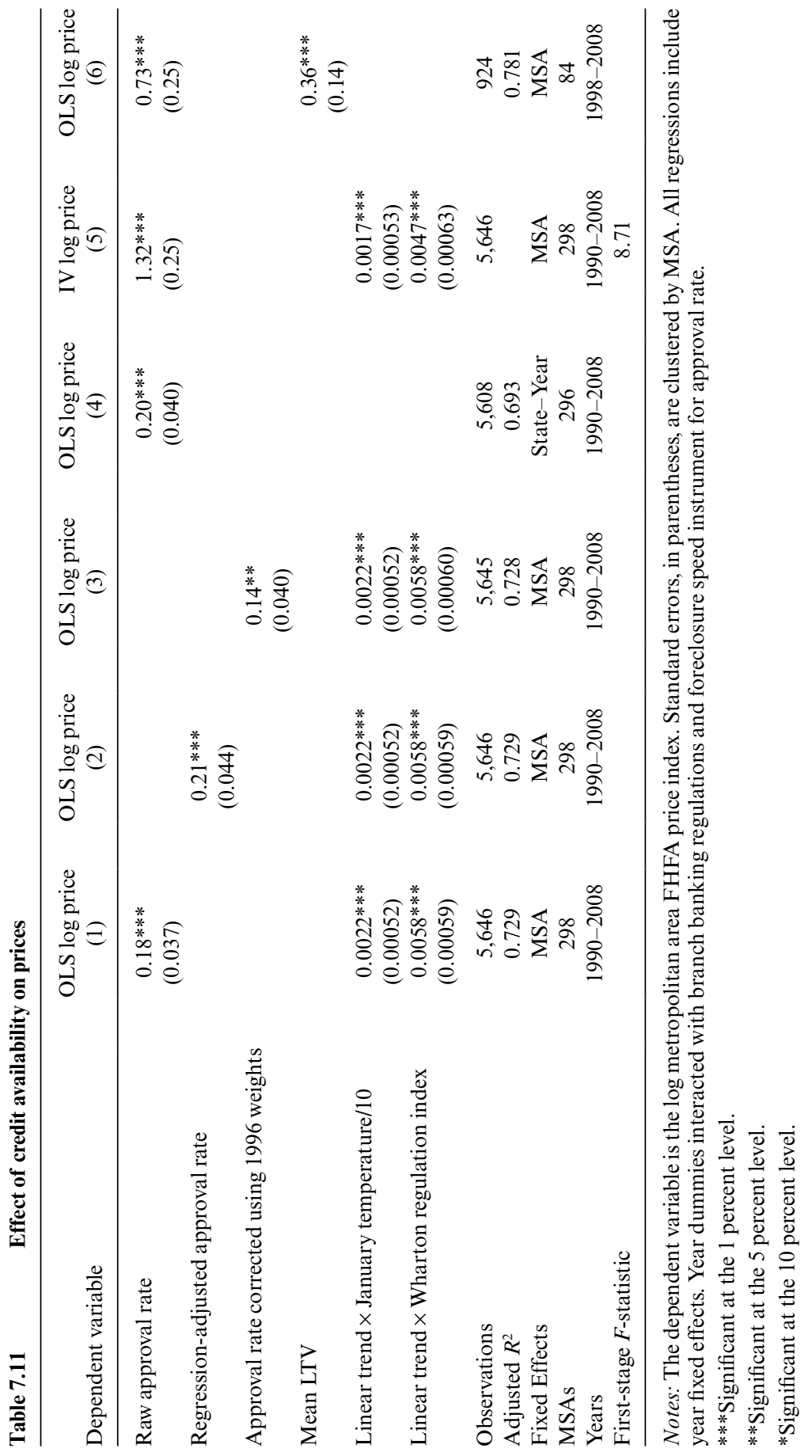


similar in magnitude. Certainly, neither the theory nor evidence suggests elasticities of one or more.

While these estimated price impacts are modest, the observed positive relationship in these regressions could reflect reverse causality or omitted variables that drive both prices and approval rates. For example, if banks associate high prices today with even higher price appreciation in the future, that could lead them to approve riskier borrowers, which would cause the ordinary least squares relationship to be biased upwards. A second possibility is that higher prices lead to lower approval rates, because lenders recognize the longer-term mean reversion in housing markets (Glaeser and Gyourko 2006), which would cause the ordinary least squares coefficient to be biased downward.

This suggests that we should try to sign the direction of bias arising from possible reverse causality. We do so by using the January temperature and Wharton supply constraint index variables used before, which influence the demand and supply of local housing, respectively. Specifically, we interact these variables with year dummies to create instruments for housing prices. Using these instruments, we estimate the following regression of approval rates on prices, with both variables orthogonalized with respect to MSA and year fixed effects:

$$
\text { Approval Rate }_{j, t}=0.097 \times \log (\text { Price })_{j, t},
$$

where the estimated coefficient's standard error is in parentheses. ${ }^{26}$ Over these years, it seems that higher housing prices are associated with higher approval rates, suggesting that our OLS estimates from columns (1) and (3) of table 7.11 overestimate the causal impact of approval rates on prices. Appendix B provides a statistical model indicating that if this coefficient from equation (11) is accurately measured, the actual causal effect of approvals on prices is negative. While we do not believe that, the reverse linkage does raise serious doubt about whether approval rates are driving prices in a material way.

Our second approach is to use as instrumental variables (IV) the interaction between year dummies and fixed state-level regulatory characteristics toward branch banking and foreclosure. These estimates would be valid if these variables predict the underlying approval rates and do not influence the mistaken applications. These interactions are motivated by the calculations in appendix B, which suggest that approval rates will change more with global interest rates in places that have easier collection rules. But the calculation does not consider the potential correlation between these instruments and the share of people mistakenly applying for mortgages. 
Our first state-level variable, taken from Pence (2006), is the average time it takes to obtain a foreclosure in a state. That variable certainly relates to the difficulties involved in collecting on a defaulting debtor, and-if the discussion and modeling in appendix B are correct - a higher value should dampen the interest rate sensitivity. Our second state-level variable is a measure of the restrictions on branch banking obtained from Rice and Strahan (2010). When branch banking was deregulated, some states kept restrictions on branch banking while others were more open. Presumably, places with fewer branch banks should have lower operating costs, and thus would have a stronger relationship between interest rates and approval rates.

These instruments have three potential problems. The first is that they may be correlated with other noncredit-related variables that could impact housing prices. The second is that they could influence the number of people who mistakenly try to get a mortgage. The third is that they could be correlated with other banking policies, such as lower down payment requirements that also affect housing demand. We are more troubled by the first two problems than by the third. While it is certainly true that the approval rate estimates using these instruments may be biased upwards because of correlation with other bank actions, our goal is not so much to estimate a pure approval rate effect as to gauge a total effect of credit market policies.

The fifth regression of table 7.11 reports the results when using these instruments. This regression is the IV analogue to the baseline OLS specification from column (1) discussed earlier. The coefficient on the metropolitan area-specific mortgage approval rate rises to 1.32. Even though this estimated price impact is not large enough to explain much of the housing boom, as we discuss later, the larger coefficient is surprising given that our earlier calculations suggested that the OLS estimates probably are biased up, not down. Moreover, this coefficient is larger than published estimates of the price elasticity of the demand for housing, which we have argued should set the upper bound for the impact of approval rates. However, the instruments themselves are weak, and if they are correlated with other banking-related actions that foster home purchases, then they will overstate the impact of approval rates. To the extent this is the case, this coefficient still has value since our ultimate interest is in the overall impact of credit factors on housing prices.

\subsubsection{The Connection between Approval Rates and Price Growth}

In table 7.12 we look at the price increases implied by our different approval rate series. The first panel looks at the 1996 to 2006 growth period; the second panel looks at the 2006 to 2008 decline in prices. The first four estimates use the theoretically predicted elasticity (1/3) rather than the empirical estimates to test the model. The predictions are based on four different approval rate figures. The first row shows the impact of changing approval rates if we just use the raw approval rate. Since the raw rate barely changes, it unsurprisingly has a trivial impact on prices. 


$\begin{array}{cc}\mathrm{d} \ln (\mathrm{P}) / \mathrm{d} \log (\alpha) & \text { Implied } \Delta \mathrm{P} \\ \times \Delta \log (\alpha)= & (\%)\end{array}$

A Overall, 1996-2006

\begin{tabular}{lcc}
\hline Raw approval rate & $0.33 \times 0.015=$ & 0.5 \\
Approval rates assuming 0.025 annual growth in $\varphi$ & $0.33 \times 0.149=$ & 5.1 \\
$\begin{array}{l}\text { Approval rates assuming buyer growth is } 3 / 4 \text { growth in accepted } \\
\quad \text { applications }\end{array}$ & $0.33 \times 0.198=$ & 6.8 \\
$\begin{array}{l}\text { Approval rates assuming buyer growth is } 1 / 2 \text { growth in accepted } \\
\quad \text { applications }\end{array}$ & $0.33 \times 0.398=$ & 14.2 \\
Raw approval rate and IV estimate (semielasticity) & $1.3 \times 0.012=$ & 1.6 \\
Actual price growth & & 42 \\
\hline
\end{tabular}

B Decline, 2006-2008

Raw approval rate

Approval rates assuming 0.025 annual decline in $\varphi$

Approval rates assuming buyer growth is $3 / 4$ growth in accepted applications

Approval rates assuming buyer growth is $1 / 2$ growth in accepted applications

Raw approval rate and IV estimate (semielasticity)

Actual price growth

$\begin{array}{rr}0.33 \times 0.016= & 0.5 \\ 0.33 \times 0.004= & 0.1 \\ 0.33 \times-0.29= & -9.3 \\ 0.33 \times-0.58= & -18 \\ 1.3 \times 0.013= & 1.7 \\ & -10\end{array}$

Notes: This table reports back-of-the-envelope calculations in which we attempt to explain observed house price growth using various estimates of the elasticity of prices with respect to approval rates. Reported actual price growth is in log points. The estimated impacts of approval rates on prices come from theory, as discussed in the text, and from the regression reported in column (5) of table 7.11, relying on data from 1990 through 2008.

The second row shows the predicted impact of the approval rate if we assume that the underlying application rate for people who will not get a mortgage increases from 50 percent to 75 percent between 1996 and 2006. Using this assumption, the growth in the logarithm of the underlying approval rate is 0.149 (reflecting the roughly 15 percent increase in the implied approval rate), which predicts a 5 percent increase in prices. The third row measures the change in the approval rate from the change in the number of accepted applications. In this case, the logarithm of the approval rate rises by 0.198 , which gives us a predicted price increase of nearly 7 percent.

The fourth row gives the best case for the change in approval rates, where we have estimated the change in approval rates based on the change in accepted applications, assuming that fully one-half of the rise in applications reflects a rise in the approval rates. In that case, the growth in the logarithm of the underlying approval rate is 0.398 and prices are predicted to rise by 14.2 percent. We consider this to be a true upper bound on the impact of rising approval rates, as we have assumed that America moved from allowing only 50 percent of interested buyers to get a mortgage to allowing over 
80 percent of interested buyers to get a mortgage. Yet despite this massive increase in the share of possible buyers, standard housing market variables predict a price increase of only 14 percent, a quarter of the price increase that was actually observed over this time period. Since buyers should have reasonably expected the approval rate to mean revert, the price impact should surely have been lower than that amount.

The fifth row then uses our IV estimate and the actual change in approval rates. We are not comfortable using the IV estimate with our implied numbers because the IV estimate is based on a measured approval rate coefficient. Still, using these two variables again results in the implied price impact being small. These results are consistent with those of Mian and Sufi (2008), who find that expansion of credit availability at the zip code level can explain house price appreciation of only 4.3 percent from 2001 to 2005 .

The second panel of table 7.12 looks at the ability of changes in the approval rate to explain the drop in prices after 2006. The first two rows show that neither the raw approval rate nor the approval rate corrected for a 2.5 percentage point decline per year in the share of unqualified people seeking mortgages can explain any of the drop. These measures of the approval rate continued to decline during the housing collapse.

The third row shows that when we estimate approvals by using the change in the number of applications, assuming that three-quarters of the drop reflects a drop in the number of interested buyers, the logarithm of the approval rate drops by 0.29 . This implied drop can explain almost all of the fall in prices that we observe. The fourth row shows that when we assume that only one-half of the drop in successful applications comes from a decline in the number of interested buyers, we overpredict the drop in prices. The fifth row shows that even with the IV estimate of the impact of the raw approval rate, that variable cannot explain the decline.

Our ability to explain changes in prices with changes in the approval rates is quite limited. We lack either compelling time series information about the changes in the relevant approval rate and compelling empirical estimates of the connection between approval rates and prices. We attempt to compensate for these shortcomings by using theory to give us a predicted connection between prices and approval rates. Our theoretical predictions are in line with what we see in the data. We then try a number of different approaches to use measured approval rates and the rise in the number of applications to estimate the changing underlying true approval rate. Our procedures suggest that at most a third of the rise in prices can be explained with rising approval rates, and that figure requires extremely aggressive assumptions. Our best guess is that the impact of approval rates is substantially less than that. However, it is quite possible that a decline in the approval rate can explain much of the national price drop since 2006. 


\subsection{Impact of Leverage: Initial Loan-to-Value Ratios}

We now turn to down payment requirements. To investigate the possible role of this factor, we must turn to another data source because the HMDA files do not report the purchase price, making it impossible to construct an initial loan-to-value ratio. One source that does collect both purchase price and initial mortgage amount is DataQuick, a well-known data provider in the housing industry. ${ }^{27}$ This source purports to collect the universe of sales in the areas it tracks, but it does not cover the entire nation. DataQuick expanded its survey coverage in 1998, so that is the first year we can begin to put together a consistent data set across metropolitan areas.

We were able to construct initial LTVs at purchase for eighty-nine metropolitan areas across eighteen states and the District of Columbia from 1998 to $2008 .^{28}$ The number of transactions used to compute LTVs each year is listed in the first column of table 7.13. In any given year, our eighty-nine metropolitan areas comprise 35 to 40 percent of all home purchases in the nation. ${ }^{29}$ The time series pattern of transactions closely parallels that for that nation, with the number of purchases in 2005 being 95 percent greater than that in 1998, and the number in 2008 being less than half (46 percent) than that in 2005.

The remaining columns of table 7.13 detail the distribution of loanto-value ratios based on all observations in our eighty-nine metropolitan area sample. Because there still are outliers after cleaning the sample, we focus on the distribution of leverage between the tenth and ninetieth percentiles of data. ${ }^{30}$ DataQuick provides information on up to three loans, and we report calculations based on the first or primary mortgage, as well as all loans. The leftmost panel of table 7.13 reports on the tenth, twenty-fifth, fiftieth, seventy-fifth, and ninetieth percentiles of the loan-to-value ratio,

27. We are grateful to Ferreira and Gyourko (2011) for providing summary statistics on these data.

28. The metropolitan areas are from across the United States, but it is not a random sample. For example, in the Northeast Census region, we have consistent data for areas in New Jersey and Pennsylvania only. New York state and the rest of New England either are not surveyed by DataQuick or do not have such data over the full 1998 to 2008 time period we are studying in this section. The Midwest and West regions of the country are better represented. States in the Midwest region with metropolitan areas consistently surveyed include Illinois, Michigan, Minnesota, Nebraska, Ohio, and Wisconsin. In the West, the states of Arizona, California, Colorado, Nevada, Oregon, and Washington are well covered. In the South region, metropolitan areas from Florida, Maryland, Oklahoma, and Tennessee are represented. A complete list is available upon request.

29. For example, we have 3.039 million sales observations in the peak year of 2005. This is about 37 percent of the combined 8.3 million sales of existing plus new home sales according to the National Association of Realtors and US Census.

30. For example, we only include observations that are coded as arms-length transactions by DataQuick. We also restrict the sample to homes with sales prices between $\$ 4,000$ and $\$ 7,500,000$. This largely eliminates a number of $\$ 0$ trades, as well as a very few extremely expensive homes. We also winsorize the data so that the bottom and top 1 percent of observations are coded at the first and ninety-ninth percentile values in the distribution. Even after this cleaning, some very high loan-to-value ratios above one remain. 


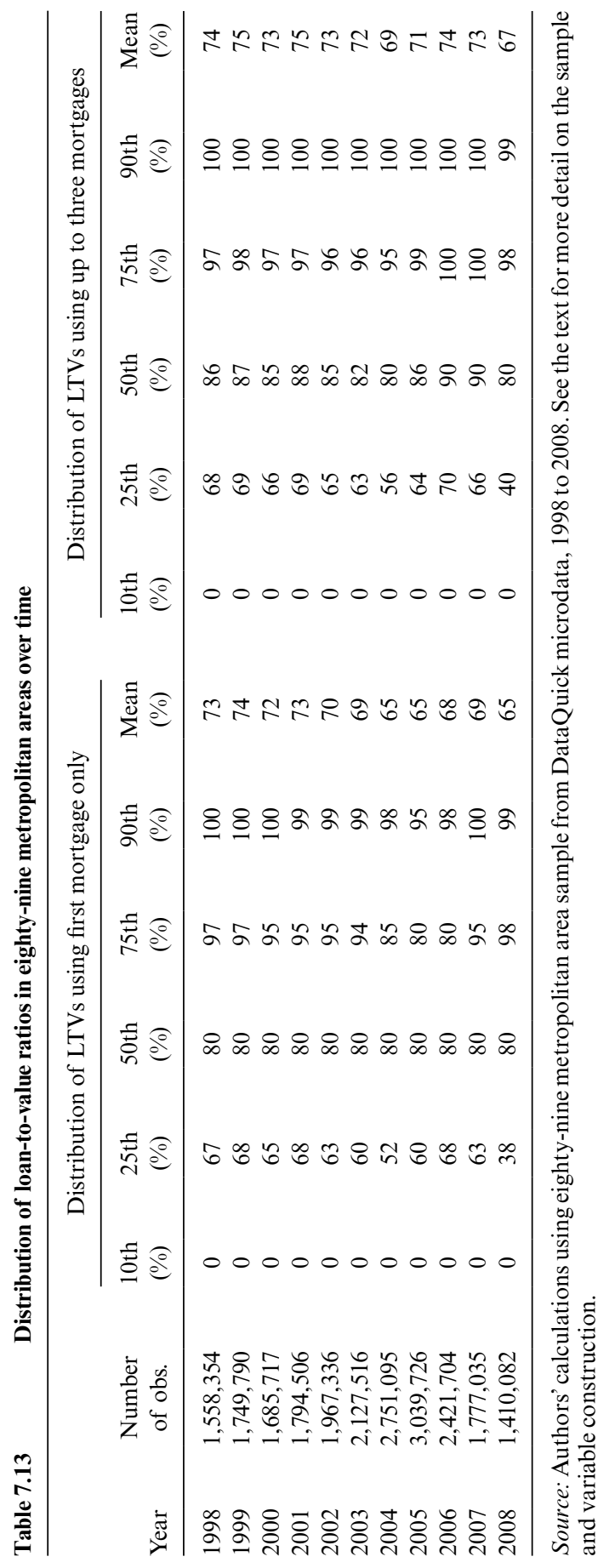




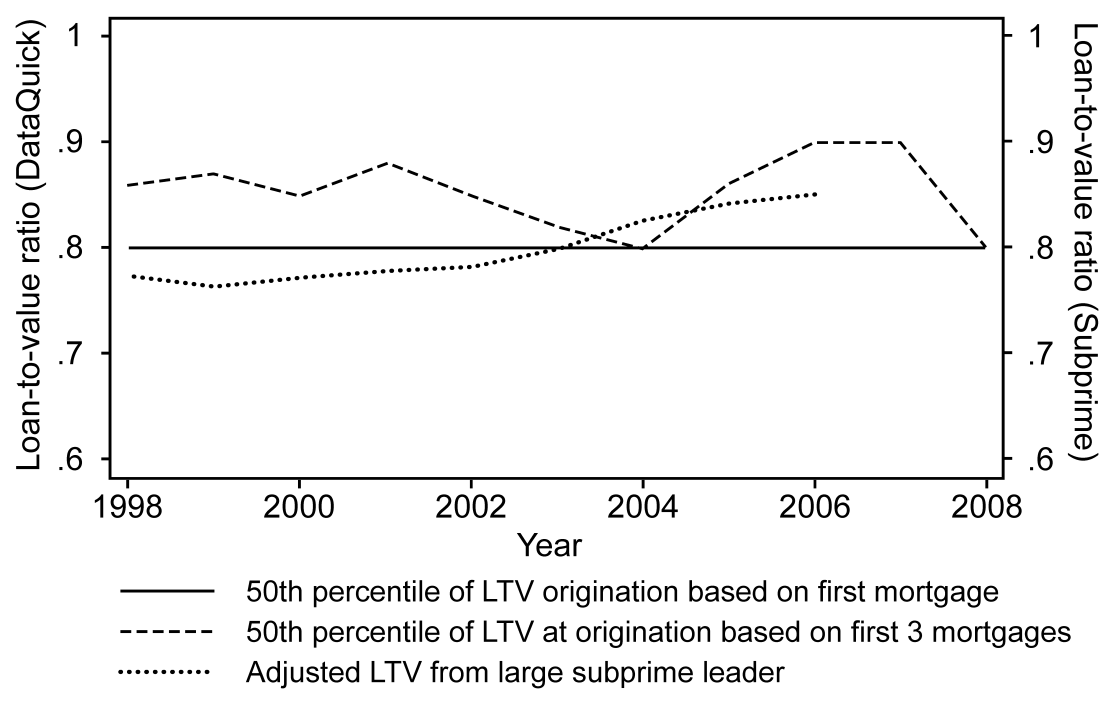

Fig. 7.6 Measures of loan-to-value ratios at origination

Sources: DataQuick data from eighty-nine metropolitan areas and applications to a large subprime lender from Amit Seru.

as well as the mean, for our full sample using only the first mortgage in the numerator. The right-most panel reports the analogous data using the sum of up to three mortgages in the numerator of the loan-to-value ratio.

There are a number of interesting features about these data. First, the results suggest that having a data source that includes junior liens could be important. Except for two years (2004 and 2008), there is a 5 to 10 percentage point difference in median LTVs, which implies that using only first mortgages will underestimate the typical home purchaser's degree of leverage. In our statistical analysis following, we use the LTV data based on all mortgage debt. Second, there has long been a large fraction of home buyers who purchase with little or no equity. At least 10 percent of purchasers in virtually every year are able to buy with no equity. ${ }^{31}$ At least one-quarter have been able to buy their homes with no more than 5 percent equity (when one counts all the mortgages, not just the first lien). There has been remarkably little change in this fraction over time, too. Similarly, the median first mortgage has been for 80 percent of home value throughout the past 12 years, as shown in the solid line of figure 7.6. The median LTV using all mortgage debt was no higher in 2005 than it was in 1999. As shown in the dashed line of figure 7.6, it did peak in 2006 and 2007, before falling sharply in 2008, so

31. A closer look at the data showed that some borrowers clearly are able to finance more than 100 percent of their purchase price. In the San Francisco market for example, lenders record a purchase price and an internal appraisal value. Our LTVs are based on the purchase price. However, internal bank appraisals tend to be higher whenever the LTV is greater than one. 
there is some interesting variation right around the housing market peak. Third, at least 10 percent of purchasers each year buy with all cash. And, there is relatively more variation in the fraction of buyers using substantial equity to purchase in their homes. In particular, there has been a sharp increase in the fraction putting down at least 60 percent equity between 2007 and 2008, as shown in the columns reporting LTVs for the twenty-fifth percentile of our sample distribution.

The results from our model already suggested that down payment changes are unlikely to have a major impact on house prices. The relative paucity of variation in LTVs over time suggests that home buyer leverage will not have much explanatory power empirically, either. While that is indeed the case, as we shall document, one needs to be cautious about making sweeping judgments about the role of changing down payment ratios with these data alone.

The distribution of loan-to-value ratios themselves is not changing very much over time, but we cannot control for changes in the sample of borrowers, including potentially important intertemporal differences in their credit quality, private discount rates, and so forth, because the DataQuick files contain no such information on the purchasers. ${ }^{32}$ This could be important because we do know that the number of buyers changed substantially over time: it nearly doubled from 1998 to 2005 , before falling by over half between 2005 and 2008. The dashed-dotted line in figure 7.6 shows the regression-adjusted leverage ratio from the large subprime lender mentioned earlier. This shows a modest increase of 8 percentage points from 1998 to 2006. These national trends also may mask important heterogeneity across regions, with credit loosening concentrated in certain cities or areas. In order to capture this phenomenon, and to empirically test the model's predictions about credit availability, we next consider metropolitan area-specific LTVs.

The MSA-level data used in our regression analysis turn out to be no more variable over time than shown in table $7.13 .{ }^{33}$ The final column of table 7.11 reports the results of adding the mean metropolitan area-specific LTV to the MSA-adjusted approval rate regression. The sample size is smaller than for the approval rate regressions, as we only have LTV data beginning

32. DataQuick is one of the few sources that reports both purchase price and mortgage amount. Unfortunately, it does not report any demographic or income data on the buyers. Further progress on this issue will require the merging of data sources such as DataQuick and HMDA. It also would be useful to include some credit bureau information so that one could control for other borrowing, if one were going to use microdata. See Haughwout et al. (2011) for one promising effort in that direction. Their focus is on a better measure of speculators. In that regard, see also Chinco and Mayer (2011).

33. For example, every statement made about the aggregate data in table 7.10 applies to both Chicago (which did not experience a particularly large price boom) and Las Vegas (which did). Buyers in Las Vegas have long used higher leverage on average, with the median home buyer putting down no more than 11 percent equity in any year from 1998 to 2007 (and the equity share was 13 percent in 2008). Median LTVs are slightly lower in Chicago, but they are not appreciably more variable. In addition, at least 10 percent of buyers in both markets use all debt, and at least 25 percent use no more than 5 percent equity. The biggest difference is in the number of buyers over time. Between 1998 and 2005, the number of Chicago metropolitan area buyers expanded by 71 percent, versus 158 percent in Las Vegas (benchmarked against a 
Predicted down payment impact on price growth from data and model

\begin{tabular}{lcc}
\hline & $\mathrm{d} \ln (\mathrm{P}) / \mathrm{d}(1-\theta) \times \Delta(1-\theta)=$ & Implied $\Delta \mathrm{P}(\%)$ \\
\hline & Biggest change: $1998-2006($ median LTV $)$ & \\
From calculation in text & $0.36 \times 4 \%=$ & 1.4 \\
From estimation & $0.36 \times 4 \%=$ & 1.4 \\
Actual price growth & & 37 \\
\hline
\end{tabular}

Notes: This table reports back-of-the-envelope calculations in which we attempt to explain observed house price growth using predicted estimates of the semielasticity of prices with respect to down payment requirements. Reported actual price growth is in $\log$ points. Row 2 uses the estimated impact of down payments on prices from the regression reported in column (6) of table 7.11, relying on data from 1998 through 2008.

in 1998 and we can only cleanly match price, approval, and LTV data for eighty-four metropolitan areas. The 0.36 coefficient taken from the specification reported in column (4) of table 7.11 implies that as loan-to-value levels rise by 10 percent, prices rise by 3.6 percent. Note that the approval rate coefficient still is higher (0.76) in this OLS estimation, which uses a more restricted sample of metropolitan areas and years than the other regressions.

We also replicated table 7.11 using a measure of construction intensity, rather than prices, as the dependent variable. Those specifications are reported in table 7C.2, in the appendix. Once again we find that these credit market controls do not explain the bulk of the variation in single-family home construction, nor do they provide evidence that would invalidate the price impact results reported in this section.

Table 7.14 quantifies the potential impact of changing loan-to-value levels. Our estimated coefficient is 0.36 (from column [6] of table 7.11). Because the mean LTV did not change between 1998 and 2006 (when counting all loans, not just the first mortgage, as debt), it cannot explain the house price boom over this time span. Median LTVs are more volatile, rising from 86 percent in 1998 to 90 percent in 2006. The impact of this 4 percentage point change is depicted in the top part of table 7.14. Given our estimated coefficient, this predicts about a 2 percent rise in prices. The actual increase in prices during this period was 0.37 log points, so changes in leverage seem to have a very small ability to explain price growth over the full extent of the boom.

There is a 10 percentage point rise in median LTVs between 2004 and 2006 , followed by a 10 point decline from 2006 to 2008 . Given our model and regression results, this change would be associated with a 3 to 6 point change in house prices. Actual house values fell by about $0.1 \log$ points during the 2006 to 2008 bust, so this variable could be responsible for an economically meaningful amount of the drop in prices. However, it cannot account for much of the boom.

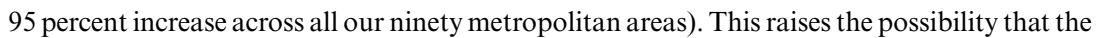
nature of buyers changed more in potentially important ways in Las Vegas. As noted earlier, we simply cannot control for this in our analysis. 


\subsection{Conclusion: So What Did Cause the Housing Bubble?}

Interest rates do influence house prices, but they cannot provide anything close to a complete explanation of the great housing market gyrations between 1996 and 2010. Over the long 1996 to 2006 boom, they cannot account for more than one-fifth of the rise in house prices. Their biggest predictive influence is during the 2000 to 2005 period, when long rates fell by almost 200 basis points. That can account for about 45 percent of the run-up in home values nationally during that half-decade span. However, if one is going to cherry-pick time periods, it also must be noted that falling real rates during the 2006 to 2008 price bust simply cannot account for the 10 percent decline in FHFA indexes for those years.

There is no convincing evidence from the data that approval rates or down payment requirements can explain most or all of the movement in house prices either. The aggregate data on these variables show no trend increase in approval rates or trend decrease in down payment requirements during the long boom in prices from 1996 to 2006. However, the number of applications and actual borrowers did trend up over this period (and fall sharply during the bust), which raises the possibility that the nature of the marginal buyer was changing over time. Carefully controlling for that requires better and different data, so our results need not be the final word on these two credit market traits.

This leaves us in the uncomfortable position of claiming that one plausible explanation for the house price boom and bust, the rise and fall of easy credit, cannot account for the majority of the price changes, without being able to offer a compelling alternative hypothesis. The work of Case and Shiller (2003) suggests that home buyers had wildly unrealistic expectations about future price appreciation during the boom. They report that 83 to 95 percent of purchasers in 2003 thought that prices would rise by an average of around 9 percent per year over the next decade. It is easy to imagine that such exuberance played a significant role in fueling the boom.

Yet, even if Case and Shiller are correct, and overoptimism was critical, this merely pushes the puzzle back a step. Why were buyers so overly optimistic about prices? Why did that optimism show up during the early years of the past decade and why did it show up in some markets but not others? Irrational expectations are clearly not exogenous, so what explains them? This seems like a pressing topic for future research.

Moreover, since we do not understand the process that creates and sustains irrational beliefs, we cannot be confident that a different interest rate policy would not have stopped the bubble at some earlier stage. It is certainly conceivable that a sharp rise in interest rates in 2004 would have let the air out of the bubble. But this is mere speculation that only highlights the need for further research focusing on the interplay between bubbles, beliefs, and credit market conditions. 


\section{Appendix A}

Table 7A.1

Mortgage approval coefficients

\begin{tabular}{|c|c|c|c|}
\hline \multicolumn{2}{|l|}{ Applicant sex ${ }^{a}$} & \multicolumn{2}{|c|}{ Ethnicity $^{\mathrm{b}}$} \\
\hline Joint application & 0.021 & Asian & -0.024 \\
\hline Female applicant & 0.031 & Black & -0.151 \\
\hline Unknown & 0.009 & Hispanic & -0.084 \\
\hline & & Native American & -0.132 \\
\hline & & Pacific Islander & -0.099 \\
\hline & & Unknown & -0.172 \\
\hline \multicolumn{4}{|c|}{ Quantile of income ${ }^{c}$} \\
\hline 1 & -0.224 & & \\
\hline 2 & -0.136 & & \\
\hline 3 & -0.098 & & \\
\hline 4 & -0.085 & & \\
\hline 5 & -0.054 & & \\
\hline 6 & -0.027 & & \\
\hline 7 & -0.039 & & \\
\hline 8 & -0.040 & & \\
\hline 9 & -0.008 & & \\
\hline 10 & -0.032 & & \\
\hline 11 & 0.022 & & \\
\hline 12 & 0.007 & & \\
\hline 14 & 0.023 & & \\
\hline 15 & 0.020 & & \\
\hline 16 & 0.026 & & \\
\hline 17 & 0.036 & & \\
\hline 18 & 0.019 & & \\
\hline 19 & 0.031 & & \\
\hline 20 & 0.035 & & \\
\hline 21 & 0.010 & & \\
\hline 22 & 0.021 & & \\
\hline 23 & 0.019 & & \\
\hline 24 & 0.004 & & \\
\hline 25 & -0.018 & & \\
\hline Unknown & 0.021 & & \\
\hline
\end{tabular}

Notes: Coefficients are reported from a linear probability model in which mortgage approval is regressed on the covariates reported above, a full set of MSA dummies, and a full set of interactions between the income quantiles and applicant sex. The regression includes 13,920,695 mortgage applicants from the 2006 Home Mortgage Disclosure Act data. Applicants are dropped if they have an explicit federal guarantee from the FHA, VA, FSA, or RHS; if they withdrew the application (following Munnell et al., 1996); or if they have invalid geographic coding.

${ }^{\text {a}}$ Male applicant is omitted.

${ }^{\text {b}}$ White is omitted.

${ }^{\mathrm{c}}$ Median quantile (13) is omitted. 


\section{Appendix B}

\section{Empirical Methods}

\section{One Instrument Estimation}

We let $\tilde{P}_{j t}$ and $\tilde{A}_{j t}$ reflect the price and approval rates in area $j$ at time $t$ that have already been orthogonalized with respect to other variables such as the metropolitan area and year fixed effects. We then assume that $\tilde{P}_{j t}=\delta \tilde{A}_{j t}$ $+\varepsilon_{j}$ and $\tilde{A}_{j t}=\gamma \tilde{P}_{j t}+\varepsilon_{j}$ or $\tilde{P}_{j t}=\left(\varepsilon_{j}+\delta \varepsilon_{j}\right) /(1-\gamma \delta)$ and $\tilde{A}_{j t}=\left(\varepsilon_{j}+\gamma \varepsilon_{j}\right) /(1-\delta \gamma)$. The OLS estimate, denoted $\hat{\beta}$, found by regressing price on approval yields:

$$
\frac{\delta+\gamma \frac{\operatorname{Var}\left(\varepsilon_{j}\right)}{\operatorname{Var}\left(\varepsilon_{\mathrm{j}}\right)}}{1+\gamma^{2} \frac{\operatorname{Var}\left(\varepsilon_{j}\right)}{\operatorname{Var}\left(\varepsilon_{j}\right)}}
$$

which is greater than $\delta$ (for positive $\gamma$ ) whenever $1>\delta \gamma$. If we let

$$
R=\frac{\operatorname{Var}\left(\tilde{P}_{j t}\right)}{\operatorname{Var}\left(\tilde{A}_{j t}\right)}=\frac{\delta_{2}+\frac{\operatorname{Var}\left(\varepsilon_{j}\right)}{\operatorname{Var}\left(\varepsilon_{\mathrm{j}}\right)}}{1+\gamma^{2} \frac{\operatorname{Var}\left(\varepsilon_{j}\right)}{\operatorname{Var}\left(\varepsilon_{j}\right)}},
$$

or $\left(R-\delta^{2}\right) /\left(1-R \gamma^{2}\right)=\left(\operatorname{Var}\left(\varepsilon_{j}\right)\right) /\left(\operatorname{Var}\left(\varepsilon_{j}\right)\right)$, it follows that $\delta$ solves $\delta^{2}\left(\hat{\beta} \gamma^{2}-\gamma\right)+$ $\delta\left(1-R \gamma^{2}\right)+\gamma R-\hat{\beta}=0$. Thus $\delta=\left(R \gamma^{2}-1 \pm \sqrt{\left(R \gamma^{2}-1\right)^{2}-4\left(\hat{\beta} \gamma^{2}-\gamma\right)(\gamma R-\hat{\beta})}\right) /$ $\left(2\left(\hat{\beta} \gamma^{2}-\gamma\right)\right)$. We have estimated $\hat{\beta}$ to be 0.26 , and the estimated value of $\gamma$ is 0.058 . The ratio of the variance of prices (orthogonalized with respect to year and metropolitan area fixed effects) to the variance of approval rates (orthogonalized with respect to the same variables) is 6.7. These suggest that $\delta$ must either equal -0.13 or 17.2 , and 17.2 is inadmissible since it would imply a negative value of $\left(\operatorname{Var}\left(\varepsilon_{j}\right)\right) /\left(\operatorname{Var}\left(\varepsilon_{j}\right)\right)$.

\section{The Use of Regulations-Year Interactions as Instruments}

The net present value of an infinite horizon loan of one dollar at interest rate $R$, which has a probability of defaulting equal to $\pi_{\text {Def }}$ in each period, equals $\sum_{j=1}^{\infty}\left(\left(1-\pi_{\text {Def }}\right) /\left(1+\rho_{\text {Bank }}\right)\right)^{j}\left(R+\pi_{\text {Def }} \omega\right) /\left(1-\pi_{\text {Def }}\right)$, where $\rho_{\text {Bank }}$ is the bank's discount rate, and $\omega$ is the recovery rate for defaulted loans (beyond paying the last period's interest). The zero profit condition then implies that $\left(R-\rho_{\text {Bank }}\right) /(1-\omega)=\bar{\pi}_{\text {Def }}$, where $\bar{\pi}_{\text {Def }}$ reflects the maximum default risk that the bank will take on, assuming that there is a maximum value of $R$ (otherwise there would never be a maximum default risk).

Differentiating this expression with respect to the "global" interest rate tells us that $\left(\partial \bar{\pi}_{\text {Def }}\right) /\left(\partial \rho_{\text {Global }}\right)=(\partial R) /\left(\partial \rho_{\text {Global }}\right)-\left(\partial \rho_{\text {Bank }}\right) /\left(\partial \rho_{\text {Global }}\right) /(1-\omega)$, which is negative as long as $\partial R / \partial \rho_{\text {Global }}<\partial R / \partial \rho_{\text {Bank }} / \partial \rho_{\text {Global }}$, which we assume to be 
the case. Moreover, if the derivatives of $R$ and $\rho_{\mathrm{Bank}}$ are independent of $\omega$, the recovery rate, then $\left(\partial^{2} \bar{\pi}_{\text {Def }}\right) /\left(\partial \rho_{\text {Global }} \partial \omega\right)=(\partial R) /\left(\partial \rho_{\text {Global }}\right)-\left(\partial \rho_{\text {Bank }}\right) /\left(\partial \rho_{\text {Global }}\right) /$ $(1-\omega)^{2}<0$, so this effect will be stronger in places where the recovery rate is higher. If we think that larger banks are more globally connected, then $\partial \rho_{\text {Bank }} / \partial \rho_{\text {Global }}$ will be higher for those larger banks and so $\partial \bar{\pi}_{\text {Def }} / \partial \rho_{\text {Global }}$ will be larger in magnitude as well.

\section{Appendix C}

\section{Interest Rates and Housing Construction}

Table 7C.1 repeats the regressions of table 7.6 using construction, rather than housing, as the dependent variable. We use building permits as reported by the US Census Bureau in its Manufacturing, Mining and Construction Statistics data, with the log of the national number being the dependent variable in table 7C.1's specifications. ${ }^{34}$ Not only is construction intrinsically interesting due to its impact on the larger economy, it also helps provide a check on our price results. Because construction statistics typically are better measured than house prices due to a permit being required for each home, finding an economically and statistically strong link between interest rates and building activity would at least raise the possibility that the relatively weak relationship between prices and rates is due to measurement in the former. ${ }^{35}$

Regressions (1) and (2) show the time series relationship between the tenyear rate and the logarithm of the number of single-family permits in the country as a whole. ${ }^{36}$ The univariate coefficient is -8.27 , with a standard error or 4.26. As with prices, the interest rate elasticity falls dramatically when a time trend is included, as shown in column (2). Construction levels, as well as housing prices, have been trending upwards over the past three decades. The results in columns (3) and (4) show no significant interest elasticities when we limit the sample to the period after 1985.

Regression (5) presents a changes-on-changes specification, yielding a coefficient of -4.82 that is not precisely estimated. Regression (6) reports

34. The data are available at http://censtats.census.gov/bldg/bldgprmt.shtml.

35. An independent impact is certainly possible, since builders may rely on financing for duration of their projects.

36. Not only is the interest rate impact on building activity interesting in its own right, but if one were willing to make a very specific assumption about the magnitude of the elasticity of housing supply (including that the elasticity is constant across areas), then the estimated elasticities reported in table 7C.1 provide an alternative means of evaluating the house priceinterest rate relationship. For example, if we were to accept Topel and Rosen's (1988) national supply elasticity of two, we would expect the interest rate elasticity of construction to be approximately two times the price elasticities (under that admittedly strong assumption). 


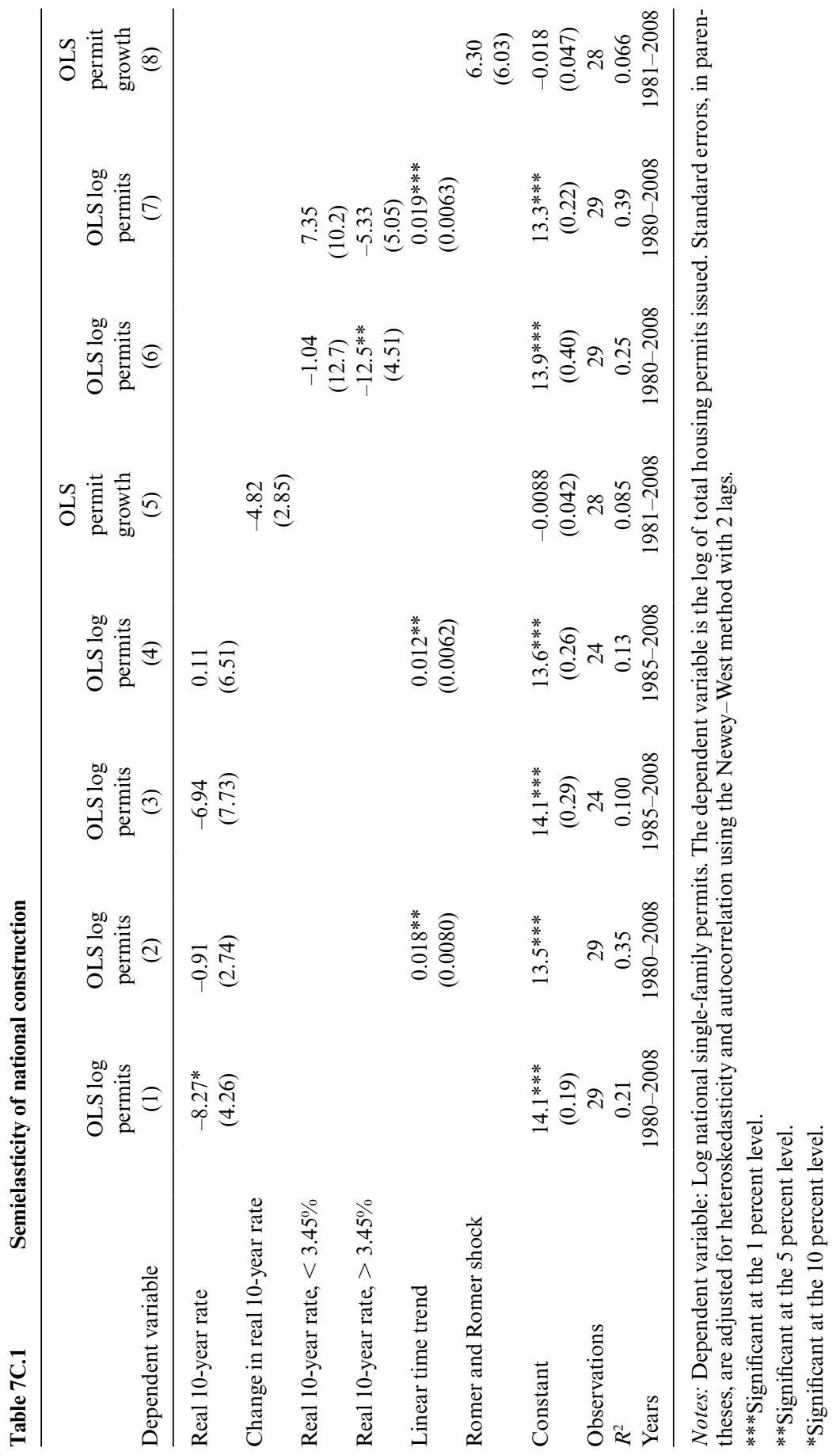


results when we estimate interest rate effects for low and high rate periods. Note that the results are the reverse of those for prices - there is a large effect of lowering interest rates from high levels, but not from low levels. Perhaps this has something to do with builders' capacity to fund themselves changing discretely when rates fall from high levels, but not from low ones. In any event, building activity goes up much more when rates fall a given amount from a high level rather than a low one. ${ }^{37}$ Finally, in regression (8), we find that the Romer and Romer variable has a modest, but imprecisely estimated, correlation with new supply.

We have also estimated the analogues to table 7C.1 for high versus low supply elasticity markets, using our quantity measure as the dependent variable. We never find a statistically or economically significant relationship in any specification. Thus, there is no evidence that interest rate sensitivity of quantities in the housing markets differs appreciably across markets by their supply side fundamentals.

Appendix table 7C.2 reports the analogue to table 7.11, using the log of single-family permits, rather than the FHFA price index, as the dependent variable. The first regression shows that a 10 percent increase in the approval rate is associated with a $0.10 \log$ point increase in the construction rate. As before, if we thought the price elasticity of housing supply was two, then we would divide these particular permit coefficients in half to obtain the implied price effects. The ratio of the elasticity of construction with respect to the approval rate divided by the price elasticity of housing with respect to the approval rate should equal the elasticity of housing supply. Comparing the relevant numbers from table 7.11 and table 7C.2 finds a ratio of 5.6, which is substantially higher than the elasticity of 2 reported in Topel and Rosen (1988).

When state-year fixed effects are controlled for (column [4]), the coefficient on approval rates becomes only marginally significant. The IV regression using the interest rate interactions (column [2]) yields a much higher coefficient of 2.37 , which is relatively close to two times the 1.32 coefficient found in table 7.11. Regression (6) includes both the approval rate and the loan-to-value measure. The approval rate coefficient is substantially higher for this set of metropolitan areas, while the loan-to-value coefficient is positive but insignificant.

37. This change relative to prices does not appear to be due to construction activity growing all that much less than real prices during the boom. From 1996 to 2005 (when construction peaked), total housing permits in the United States increased by 40 percent (single-family permits rose by 48 percent over the same time period), compared to a 49 percent rise in the FHFA price index from 1996 to 2006. 


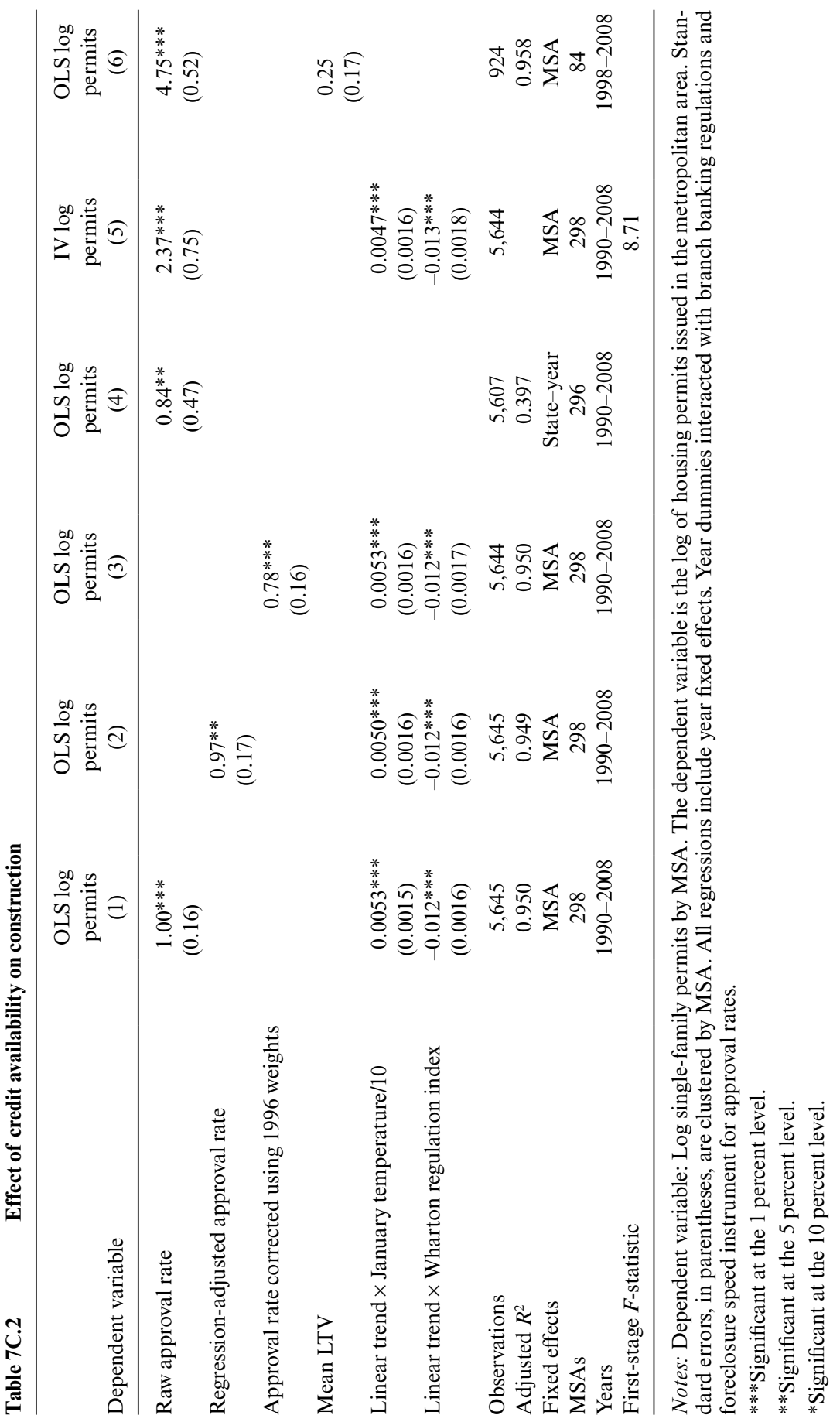




\section{References}

Bubb, Ryan, and Alex Kaufman. 2009. "Securitization and Moral Hazard: Evidence from a Lender Cutoff Rule." Federal Reserve Bank of Boston Public Policy Discussion Paper no. 09-5, September.

Campbell, John Y., and Joao F. Cocco. 2011. "A Model of Mortgage Default." Unpublished Paper, Harvard University, October.

Case, Karl E., and Robert J. Shiller. 2003. "Is There a Bubble in the Housing Market?” Brookings Papers on Economic Activity 2:299-342.

Chinco, Alex, and Chris Mayer. 2011. "Noise Traders, Distant Speculators and Asset Bubbles in the Housing Market.” Working Paper, NYU Stern School of Business, October 15.

Coleman, Major D., Michael LaCour-Little, and Kerry D. Vandell. 2008. "Subprime Lending and the Housing Bubble: Tail Wags Dog?" Working Paper, University of California, Irvine. Available at SSRN: http://papers.ssrn.com/sol3/papers .cfm?abstract_id=1262365.

Favilukis, Jack, Sydney Ludvigson, and Stijn Van Nieuwerburgh. 2010, "Macroeconomic Implications of Housing Wealth, Housing Finance, and Limited RiskSharing in General Equilibrium." Social Science Research Network Working Paper, May 7. Available at SSRN: http://ssrn.com/abstract=1602163.

Ferreira, Fernando, and Joseph Gyourko. 2011. "Anatomy of the Beginning of the Housing Boom: US Neighborhoods and Metropolitan Areas, 1993-2009." Working Paper, University of Pennsylvania. http://real.wharton.upenn.edu/ fferreir/ documents/housing\%20boom\%20August $\% 2018 \% 202011$.pdf.

Ferreira, Fernando, Joseph Gyourko, and Joseph Tracy. 2010. "Housing Busts and Household Mobility.” Journal of Urban Economics 68 (1): 34-45.

Garriga, Carlos. 2009. "Lending Standards in Mortgage Markets." Economic Synopses, no. 23, Federal Reserve Bank of St. Louis. Posted May 6.

Glaeser, Edward L., Joshua D. Gottlieb, and Joseph Gyourko. 2010. "Can Cheap Credit Explain the Housing Boom?" NBER Working Paper no. 16230. Cambridge, MA: National Bureau of Economic Research.

Glaeser, Edward L., and Joseph Gyourko. 2006. "Housing Dynamics.” NBER Working Paper no. 12787. Cambridge, MA: National Bureau of Economic Research.

\section{(6): Article 3.}

Glaeser, Edward L., Joseph Gyourko, and Albert Saiz. 2008. "Housing Supply and Housing Bubbles.” Journal of Urban Economics 64 (2): 198-217.

Greenspan, Alan. 2010. "The Crisis." Brookings Papers on Economic Activity 2010 (1): 201-46. Washington, DC: Brookings Institution.

Gyourko, Joseph, Albert Saiz, and Anita Summers. 2008. "A New Measure of the Local Regulatory Environment for Housing Markets." Urban Studies 45 (3): 693 729.

Haughwout, Andrew, Donghoon Lee, Joseph Tracy, and Wilbert van der Klaauw. 2011. "Real Estate Investors, the Leverage Cycle and the Housing Market Crisis." Federal Reserve Bank of New York Staff Report no. 514, September.

Haurin, Donald R., Susan M. Wachter, and Patric H. Hendershott. 1995. "Wealth Accumulation and Housing Choices of Young Households: An Exploratory Investigation." NBER Working Paper no. 5070. Cambridge, MA: National Bureau of Economic Research.

Himmelberg, Charles, Christopher Mayer, and Todd Sinai. 2005. "Assessing High House Prices: Bubbles, Fundamentals and Misperceptions." Journal of Economic Perspectives 19 (4): 67-92. 
Keys, Benjamin J., Tanmoy Mukherjee, Amit Seru, and Vikrant Vig. 2009. "Financial Regulation and Securitization: Evidence from Subprime Mortgage Loans." Journal of Monetary Economics 56 (5): 700-20.

2010. "Did Securitization Lead to Lax Screening? Evidence from Subprime Loans." Quarterly Journal of Economics 125 (1): 307-62.

Khandani, Amir, Andrew W. Lo, and Robert C. Merton. 2009. "Systemic Risk and the Refinancing Ratchet Effect." NBER Working Paper no. 15362. Cambridge, MA: National Bureau of Economic Research.

Mas, Alexandre, and Enrico Moretti. 2009. "Peers at Work." American Economic Review 99 (1): 112-45.

Mayer, Christopher J., and Gary V. Engelhardt. 1996. "Gifts, Down Payments, and Housing Affordability.” Journal of Housing Research 7 (1): 59-77.

Mayer, Christopher J., and Todd Sinai. 2009. "US House Price Dynamics and Behavioral Finance." In Policy Making Insights from Behavioral Economics, edited by Christopher L. Foote, Lorenz Goette, and Stephan Meier, chapter 5. Boston: Federal Reserve Bank of Boston.

Mian, Atif, and Amir Sufi. 2008. "The Consequences of Mortgage Credit Expansion: Evidence from the US Mortgage Default Crisis." NBER Working Paper no. 13936. Cambridge, MA: National Bureau of Economic Research.

. 2009. "The Consequences of Mortgage Credit Expansion: Evidence from the US Mortgage Default Crisis." Quarterly Journal of Economics 122 (4): 1449-96. 2010. "Household Leverage and the Recession of 2007 to 2009." NBER Working Paper no. 15892. Cambridge, MA: National Bureau of Economic Research.

Mian, Atif, Amir Sufi, and Francisco Trebbi. 2008. "The Political Economy of the US Mortgage Default Crisis.” NBER Working Paper no. 14468. Cambridge, MA: National Bureau of Economic Research.

Munnell, Alicia H., Geoffrey M. B. Tootell, Lynn E. Browne, and James McEneaney. 1996. "Mortgage Lending in Boston: Interpreting HMDA Data." American Economic Review 86 (1): 25-53.

Newey, Whitney K., and Kenneth D. West. 1987. "A Simple, Positive Semi-Definite, Heteroskedasticity and Autocorrelation Consistent Covariance Matrix." Econometrica 55 (3): 703-38.

Pence, Karen M. 2006. "Foreclosing on Opportunity: State Laws and Mortgage Credit." Review of Economics and Statistics 88 (1): 177-82.

Polinsky, A. Mitchell, and David T. Ellwood. 1979. "An Empirical Reconciliation of Micro and Grouped Estimates of the Demand for Housing." Review of Economics and Statistics 61 (2): 199-205.

Poterba, James. 1984. "Tax Subsidies to Owner-Occupied Housing: An AssetMarket Approach." Quarterly Journal of Economics 99 (4): 729-52.

Poterba, James, and Todd Sinai. 2008. "Tax Expenditures for Owner-Occupied Housing: Deductions for Property Taxes and Mortgage Interest and the Exclusion of Imputed Rental Income." American Economic Review Papers and Proceedings 96 (2): 84-89.

Rice, Tara, and Philip E. Strahan. 2010. "Does Credit Competition Affect SmallFirm Finance?” Journal of Finance 65 (3): 861-89.

Romer, Christina D., and David H. Romer. "A New Measure of Monetary Shocks: Derivation and Implications." American Economic Review 94 (4): 1055-84.

Saiz, Albert. 2003. "Room in the Kitchen for the Melting Pot: Immigration and Rental Prices." Review of Economics and Statistics 85 (3): 502-21.

- 2007. "Immigration and Housing Rents in American Cities." Journal of Urban Economics 61 (2): 345-71.

_. 2008. "On Local Housing Supply Elasticity." Working Paper, The Wharton 
School. Available at SSRN: http://papers.ssrn.com/sol3/papers.cfm?abstract id=1193422.

Shiller, Robert J. 2005. Irrational Exuberance, 2nd ed. Princeton, NJ: Princeton University Press.

_ 2006. "Long-Term Perspectives on the Current Boom in Home Prices." The Economists' Voice 3 (4): 4.

Taylor, John B. 2009. Getting off Track: How Government Actions and Interventions Caused, Prolonged, and Worsened the Financial Crisis. Stanford: Hoover Institution Press.

Topel, Robert, and Sherwin Rosen. 1988. "Housing Investment in the United States." Journal of Political Economy 96 (4): 718-40. 